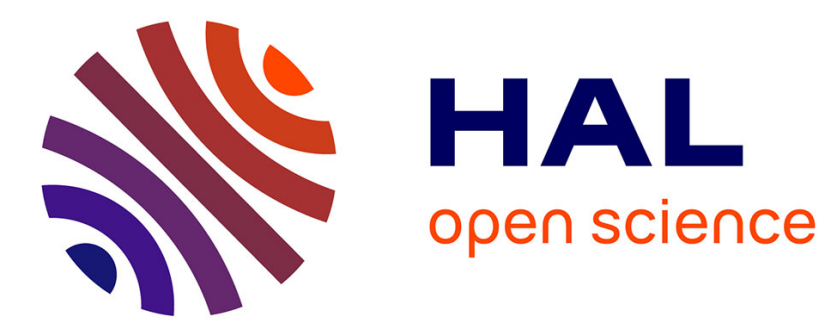

\title{
Caspase cleavage of Ets-1 p51 generates fragments with transcriptional dominant-negative function
}

Souhaila Choul-Li, Catherine Leroy, Gabriel Leprivier, Clélia Laitem, David Tulasne, Marc Aumercier

\section{- To cite this version:}

Souhaila Choul-Li, Catherine Leroy, Gabriel Leprivier, Clélia Laitem, David Tulasne, et al.. Caspase cleavage of Ets-1 p51 generates fragments with transcriptional dominant-negative function. Biochemical Journal, 2010, 426 (2), pp.229-241. 10.1042/BJ20090877 . hal-00479208

\section{HAL Id: hal-00479208 https://hal.science/hal-00479208}

Submitted on 30 Apr 2010

HAL is a multi-disciplinary open access archive for the deposit and dissemination of scientific research documents, whether they are published or not. The documents may come from teaching and research institutions in France or abroad, or from public or private research centers.
L'archive ouverte pluridisciplinaire HAL, est destinée au dépôt et à la diffusion de documents scientifiques de niveau recherche, publiés ou non, émanant des établissements d'enseignement et de recherche français ou étrangers, des laboratoires publics ou privés. 


\section{Caspase cleavage of Ets-1 p51 generates fragments with transcriptional dominant-negative function}

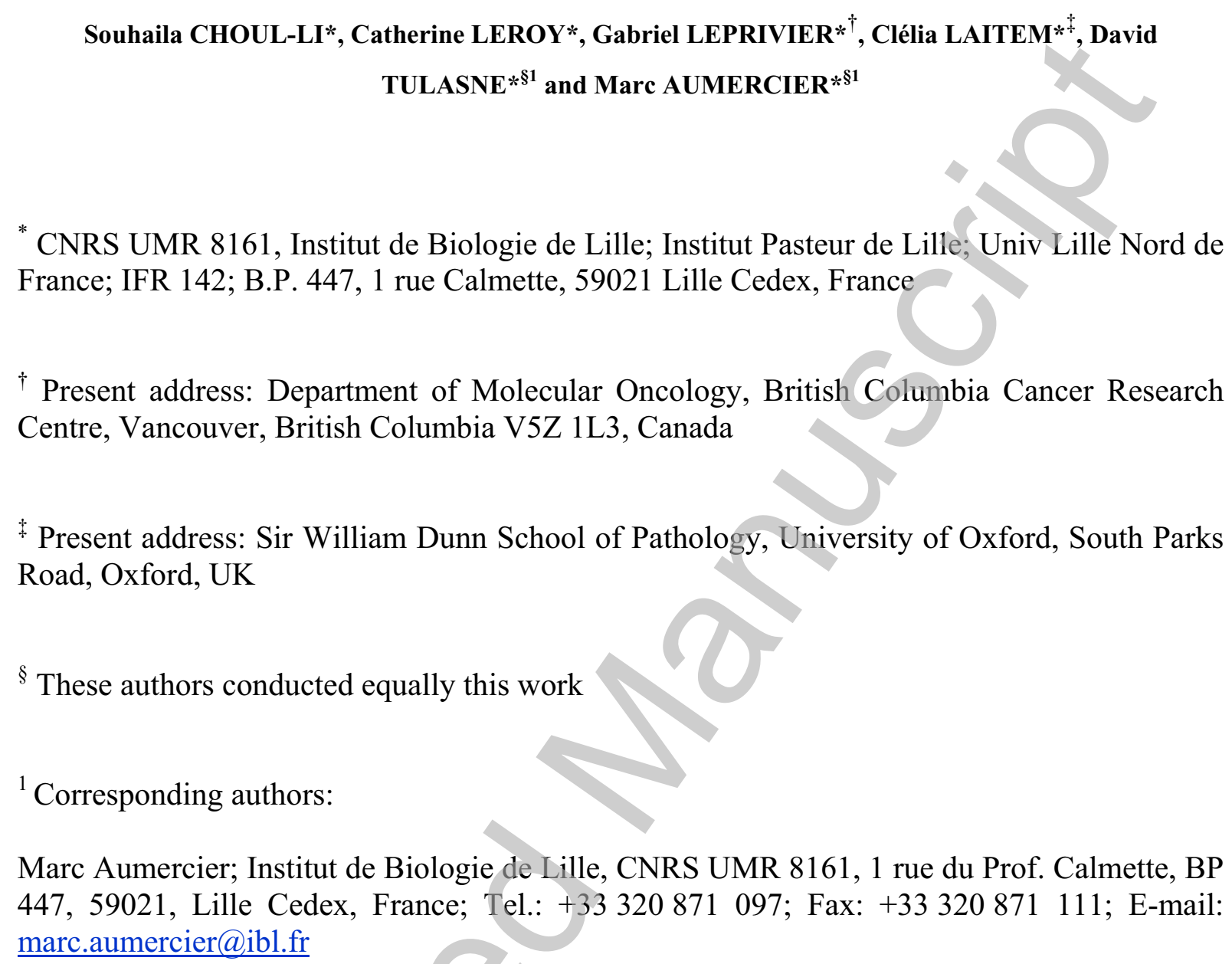

Marc Aumercier; Institut de Biologie de Lille, CNRS UMR 8161, 1 rue du Prof. Calmette, BP 447, 59021, Lille Cedex, France; Tel.: +33 320871 097; Fax: +33 320871 111; E-mail: marc.aumercier@ibl.fr

David Tulasne; Institut de Biologie de Lille, CNRS UMR 8161, 1 rue du Prof. Calmette, BP 447, 59021, Lille Cedex, France; Tel.: +33 320871 257; Fax: +33 320871 111; E-mail: david.tulasne@,ibl.fr

Short title: Caspase cleavage of Ets-1 p51

Abbreviations used: DBD, DNA binding domain; DTT, dithiotreitol; EBS, ETS-binding site; GAPDH, glyceraldehyde-3-phosphate dehydrogenase; HRP, horseradish peroxidase; TAD, transactivation domain; TORU, TPA oncogene response unit; WT, wild-type; zVAD-FMK, benzyloxycarbonyl-Val-Ala-Asp-fluoromethylketone. 


\section{SYNOPSIS}

Ets-1 is a transcription factor that plays an important role in various physiological and pathological processes, such as development, angiogenesis, apoptosis and tumour invasion. Here we demonstrate that Ets-1 p51, but not the spliced variant Ets-1 p42, is processed in a caspase-dependent manner in Jurkat T-leukaemia cells undergoing apoptosis, resulting in three C-terminal fragments Cp20, Cp17 and Cp14 and a N-terminal fragment, Np36. In vitro cleavage of Ets-1 p51 by caspase-3 produces fragments consistent with those observed in cells undergoing apoptosis. These fragments are generated by cleavage at three sites located in the exon VII-encoded region of Ets-1 p51. This region is absent in the Ets-1 p42 isoform, which therefore cannot be cleaved by caspases. In Ets-1 p51, cleavage generates C-terminal fragments containing the DNA binding domain but lacking the transactivation domain. The Cp17 fragment, the major cleavage product generated during apoptosis, is devoid of transcriptional activity and inhibits Ets-1 p51-mediated transactivation of target genes by competing with Ets-1 p51 for binding to Ets-binding sites present in the target promoters. In this study, we demonstrate that caspase cleavage of Ets-1 within the exon VII-encoded region leads to specific down-regulation of the Ets-1 p51 isoform during apoptosis. Further, our results establish that caspase cleavage generates a stable C-terminal fragment that acts as a natural dominant-negative of the full-length Ets-1 p51 protein.

Key words: Ets-1 isoforms, apoptosis, caspases, exon VII-encoded region, dominant negative, transcriptional regulation. 
69

70

71

72

73

74

75

76

77

\section{INTRODUCTION}

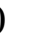

Apoptosis is a genetically controlled form of cell death that plays a critical role during development and tissue homeostasis by ensuring the removal of damaged or unnecessary cells [1]. Apoptotic stimulation leads to the cascade activation of cysteine proteases called caspases, which carry out the apoptotic program by cleaving numerous substrates [2]. Disruption in the regulation of apoptosis underlies the pathogenesis of many human diseases, including autoimmune diseases, neurogenerative disorders and cancers [3].

Since caspase-mediated proteolysis is crucial for the apoptotic process [4], identification of the molecular targets of caspases is necessary to better understand apoptotic signal transduction. Indeed, several classes of cellular proteins have been shown to be cleaved by caspases during apoptotic cell death [5]. This usually results in either inactivation or activation of proteins that protect living cells or promote cell death. Among those substrates, several transcription factors are inactivated during apoptosis by caspase-3 including SRF [6], Retinoid Acid Receptor- $\alpha$ (RAR- $\alpha$ ) [7] and NF-kappa B p65/RelA subunit [8]. Likewise, in the Ets transcription factor family, Fli-1 has been shown to be cleaved in murine preB leukemic cells undergoing programmed cell death by a caspase-like activity and in vitro by caspase-3 [9].

Ets-1 is the founding member of the Ets family characterised by a well-conserved DNA-binding domain (DBD), called the ETS domain. It regulates gene expression by binding to specific DNA elements, called Ets-binding sites (EBS), found in the promoters of its target genes $[10,11]$. By binding to these elements, Ets-1 activates the transcription of various genes involved in numerous cellular mechanisms such as development, angiogenesis, proliferation and apoptosis [12]. However, when overexpressed, Ets-1 is involved in the development of 
93 invasive pathologies such as rheumatoid arthritis [13], glomerulonephritis [14] and cancers $94[12]$.

In humans, two isoforms of Ets-1 have been described: p51, the predominant, fulllength isoform, and p42, a shorter, alternatively spliced isoform that lacks the exon VIIencoded region [15]. As a result of their respective structures, Ets-1 p51 and Ets-1 p42 isoforms have different DNA binding and transcriptional properties [16-18]. Ets-1 p51 is autoinhibited for DNA binding due to the presence of two inhibitory domains that flank and interact with its DBD [19]. To counteract autoinhibition and improve DNA binding, Ets-1 p51

101 interacts with partners, enabling them to cooperatively bind to adjacent DNA elements [20].

Ets-1 p51 can also counteract its autoinhibition without any interaction partners by binding to 103 a particular palindromic arrangement of two EBS separated by $4 \mathrm{bp}$, as in the stromelysin- 1 104 matrix metalloproteinase and the $p 53$ oncosuppressor promoters [17, 21, 22]. Two molecules 105 of Ets-1 p51 cooperatively bind to the EBS palindrome, thereby forming an Ets-1 p51/DNA/Ets-1 p51 ternary complex that is critical for full transactivation [17]. In contrast, Ets-1 p42 only forms a binary Ets-1 p42/DNA complex, which is much less efficient in 108 promoting transactivation $[17,18]$. These differences contribute to the Ets-1 isoform-specific 109 modulation of particular target genes, illustrating that Ets-1 function can be regulated through 110 the exon VII-encoded region [23, 24].

Ets-1 p51 displays pro- and anti-apoptotic functions according to the biological

112 context. Ets-1 p51 is required for the formation of a stable DNA-p53-CBP complex to induce 113 pro-apoptotic genes in the process of UV-induced apoptosis in embryonic stem cells [25].

114 Furthermore, overexpression of Ets-1 p51 in human umbilical vein endothelial cells induces 115 apoptosis under serum-deprived conditions by up-regulating pro-apoptotic genes [26]. Anti116 apoptotic functions have been ascribed to Ets-1 p51 in vascular smooth muscle cells 117 protecting them from undergoing apoptosis by activating the transcription of $\mathrm{p} 21^{\text {waf1/cip } 1}$ [27]. 
118 Moreover, Ets-1 p51 inhibits the expression of the pro-apoptotic gene bax by interacting with

119 the transcription factor Growth Factor Independent-1 (GFI-1) in the composite site present in

120 the bax promoter [28]. In contrast, Ets-1 p42 isoform expression seems to be essentially

121 associated with apoptosis. The expression of Ets-1 p42, unlike that of Ets-1 p51, promotes

122 Fas-mediated apoptosis by directly up-regulating ICE/caspase-1 gene expression in human

123 colon cancer DLD-1 cells [24, 29]. Ets-1 p42 expression can also induce apoptosis of these

124 cells in low-serum conditions [30]. Furthermore, Ets-1 p42-expressing DLD-1 cell xenografts

125 in nude mice inhibit the tumorigenicity of the DLD-1 cancer cells by inducing apoptosis [29].

126 Previous studies have shown that the basal level of Ets-1 p51 decreases in cells

127 undergoing apoptosis. For example, an apoptotic inducer, curcumin, decreases the amount of

128 Ets-1 p51 protein in human endometrial carcinoma HEC-1-A cells in a time- and dose-

129 dependent manner [31]. Likewise, flow cytometry and confocal microscopy analysis have

130 shown that Ets-1 expression is down-regulated in peripheral blood mononuclear (PBMC) and

131 bursal cells induced to apoptosis [32].

132 In this study, we demonstrate that the induction of apoptosis in human acute T-cell

133 leukaemia (Jurkat) cells causes a decrease in Ets-1 p51 levels that is associated with the

134 generation of caspase-dependent fragments. Furthermore, we characterise the mechanisms

135 and the functional consequences of Ets-1 p51 cleavage on the transcriptional modulation of

136 Ets-1 target genes.

\section{EXPERIMENTAL}

\section{Cell culture and induction of apoptosis}

140 Human Embryonic Kidney (HEK-293) cells were cultured in Dulbecco's Modified Eagle's

141 Medium (DMEM; Invitrogen ${ }^{\mathrm{TM}}$, Carlsbad, CA, USA) supplemented with $10 \%$ fetal bovine

142 serum (FBS) and $50 \mu \mathrm{g} / \mathrm{ml}$ gentamycin. To induce apoptosis, HEK-293 cells were incubated 
$14324 \mathrm{~h}$ after transfection in medium supplemented with $1 \mu \mathrm{M}$ staurosporin (Calbiochem ${ }^{\circledR}$, San

144 Diego, CA, USA) for $8 \mathrm{~h}$. Jurkat human T-leukaemia cells were cultured in RPMI 1640 145 medium (Invitrogen ${ }^{\mathrm{TM}}$ ) supplemented with 10\% FBS and $50 \mu \mathrm{g} / \mathrm{ml}$ gentamycin. To induce 146 apoptosis, Jurkat cells $\left(3 \times 10^{6}\right)$ were incubated in medium supplemented with $1 \mu \mathrm{M}$ 147 staurosporin for $4 \mathrm{~h}$. Madin-Darby Canine Kidney (MDCK) epithelial cells were cultured in 148 DMEM supplemented with $10 \%$ fetal calf serum, $50 \mu \mathrm{g} / \mathrm{ml}$ gentamycin and $100 \mu \mathrm{g} / \mathrm{ml}$ 149 penicillin-streptomycin. To induce apoptosis, MDCK cells were incubated $24 \mathrm{~h}$ after 150 transfection in medium supplemented with $10 \mu \mathrm{M}$ anisomycin (Calbiochem) for $8 \mathrm{~h}$. To 151 inhibit caspase activity, cells were preincubated for 30 min with $20 \mu \mathrm{M}$ benzyloxycarbonyl152 Val-Ala-Asp-fluoromethylketone (zVAD-FMK; Calbiochem) prior to treatment with 153 staurosporin. Rabbit synovial fibroblasts (HIG-82) cells (ATCC, Manassa, VA, CRL-1832) 154 were cultured in F-12 medium (Invitrogen ${ }^{\mathrm{TM}}$ ), supplemented with $10 \% \mathrm{FBS}$ and $50 \mu \mathrm{g} / \mathrm{ml}$ 155 gentamycin, between passage 7 and 14.

\section{Cell lysates}

158 Jurkat and HEK-293 cells were lysed by sonication (10 s, $16 \mu \mathrm{m}$ amplitude) in $100 \mu 1$ of 159 buffer $\left(50 \mathrm{mM}\right.$ Tris $\mathrm{pH} 8 ; 150 \mathrm{mM} \mathrm{NaCl} ; 0.1 \mathrm{mM}$ EDTA; Complete ${ }^{\mathrm{TM}}$ protease inhibitor 160 cocktail (Roche Diagnostics GmbH, Mannheim, Germany)). MDCK cells were suspended in $161200 \mu 1$ of lysis buffer $(25 \mathrm{mM}$ HEPES pH 7.5; $100 \mathrm{mM} \mathrm{NaCl} ; 1.5 \mathrm{mM} \mathrm{MgCl} 2 ; 0.5 \mathrm{mM}$ 162 EGTA; $0.25 \mathrm{mM}$ EDTA; 0.1\% Nonidet P-40; $10 \mathrm{mM} \mathrm{NaF;} 20 \mathrm{mM} \beta$-glycerophosphate; 1 $163 \mathrm{mM} \mathrm{Na} \mathrm{VO}_{4}, 1 \mathrm{mM}$ PMSF; $10 \mu \mathrm{g} / \mathrm{ml}$ leupeptin; $10 \mu \mathrm{g} / \mathrm{ml}$ aprotinin). Total protein 164 concentration was measured by colorimetry (Bio-Rad assay) before Western blot analysis.

\section{Expression vector construction}


167 The construction of a pcDNA3 vector expressing human Ets-1 p51 fused to a Flag tag is

168 described in ref. [33]. The pcDNA3 vector expressing human Ets-1 p42 fused to a Flag tag

169 was obtained by the same strategy as the Flag-Ets-1 p51 pcDNA3 expression vector, using the

170 human Ets-1 p42 pSG5 expression vector [17] as a template. To produce Ets-1 p51 mutants,

171 Asp (D) residues were replaced by Asn (N) residues in position 262 for D1N, 262/287/290 for

172 D3N and 262/287/290/313 for D4N using the QuickChange Site-directed Mutagenesis Kit

173 (Stratagene $^{\circledR}$, La Jolla, CA, USA). Briefly, the pcDNA3 vector expressing human Ets-1 p51

174 fused to a Flag tag was used as a template for PCR amplification, using the following primers

175 in which mutated codons are underlined: 5'-TACGATAGTTGTAAATCGCCTCACCCAG-3'

176 and 5'-CTGGGTGAGGCGATTACAACTATCGTA-3' for the D262N mutation; 5'-

177 GACAGCTTCAACTCAGAGAACTATCCGGCTGCC-3', and 5'-

178 GGCAGCCGGATAGTTCTCTGAGTTGAAGCTGTC-3' for the D287/290N mutations and

5'-CGGGACCGTGCTACCTCAATAAGGACAAG-3' 5'-

180 CTTGTCCTTATTGAGGTTAGCACGGTCCCG-3' for the D313N mutation.

181 To produce the Cp17 fragment, the sequence coding amino acids 291-441 of Ets-1 p51

182 was obtained by PCR amplification, using the following primers: 5'-

183 AATCACTAAGATCTTATCCGGCTGCCCTGCCCAACC-3'

184 TATGCGGCCGCTCACTCGTCGGCATCTGGCTTGAC-3'. The PCR product was then

185 cloned between the BamHI and NotI restriction sites in a modified pcDNA3 expression vector

186 (kindly provided by Dr D. Monté). This vector contained the coding sequence for a Flag

187 epitope followed by a BamHI site. To produce the Np36 fragment, the sequence coding amino

188 acid 1-262 of Ets-1 p51 was obtained by PCR amplification, using the following primers: 5'-

189 ATTTAAAGATCTAAGGCGGCCGTCGATCTC-3' ${ }^{\prime}$ and '-

190 AATCACTAAGATCTATCACAACTATCGTAGCTCTC-3'. The PCR product was then

191 cloned in the BamHI site of the modified pcDNA3 expression vector. For all vectors, correct 
192 insertion was checked by sequencing. The construction of the $-478 /+4$ wild-type and EBS

193 mutant human stromelysin-1 promoter pGL3 reporter vector (Promega, Madison, WI, USA)

194 and the construction of the $-607 /+51$ TORU mutant human collagenase-1 promoter pGL2

195 reporter vector are described in refs. $[17,33]$. The $-607 /+51$ wild-type human collagenase-1

196 promoter pGL2 reporter vector as well as the c-Jun and the c-Fos encoding pSG5 vectors

197 were kindly provided by Dr M. Duterque-Coquillaud.

198 The construction of the bacterial expression vector containing the cDNA sequence of 199 human Ets-1 p51 is described in ref. [17].

201 Transient transfection

202 HEK-293, HIG-82 or MDCK cells were grown in six-well plates to reach $40-60 \%$ confluence 203 at the time of transfection. Transfection of HEK-293 and HIG-82 cells was performed by 204 incubating the ExGen 500 transfection reagent, according to the manufacturer's instructions 205 (Euromedex, Souffelweyersheim, France), with $1 \mu \mathrm{g}$ of expression vectors. Transfection of 206 MDCK cells was performed using the lipofection method [34].

\section{In vitro caspase cleavage reactions}

209 After $48 \mathrm{~h}$ of transfection, HEK-293 cells and Jurkat cells were lysed in $80 \mu \mathrm{l}$ of caspase 210 buffer (20 mM PIPES pH 7.2; $100 \mathrm{mM} \mathrm{NaCl} ; 1 \%$ Chaps; $10 \%$ sucrose; $5 \mathrm{mM}$ dithiotreitol 211 (DTT); $0.05 \mathrm{mM}$ EDTA). Cell lysates were incubated $4 \mathrm{~h}$ at $37^{\circ} \mathrm{C}$ with $1 \mu \mathrm{l}$ of purified 212 caspase. Reactions were stopped by incubation at $70{ }^{\circ} \mathrm{C}$ for $1 \mathrm{~min}$ in denaturating buffer (125 213 mM Tris-HCl pH 6.8; 4\% SDS; 20\% Glycerol; 100 mM DTT). Total cell lysate proteins were 214 then analysed by Western blot. Purified active caspases were generously provided by Dr G.S.

215 Salvesen. Titration of the active recombinant caspases were obtained using in vitro cleavage 
against synthetic substrates as previously described (caspase-3, $13.9 \mu \mathrm{M}$; caspase-6, $7.5 \mu \mathrm{M}$; caspase-7, $19.7 \mu \mathrm{M}$; caspase-8, $15 \mu \mathrm{M}$; caspase-9, $41.5 \mu \mathrm{M})$ [35].

\section{Transfection and luciferase reporter gene assay}

HEK-293 cells were grown in 12 -well plates to reach $40-60 \%$ confluence at the time of transfection. Transfections were then performed by incubating the ExGen 500 transfection reagent, according to the manufacturer's instructions (Euromedex), with $500 \mathrm{ng}$ of vectors. Transfections were carried out with increasing amounts of the Cp17 or the Np36 expression vector and human stromelysin-1 or collagenase-1 promoter reporter vector in the presence or absence of the Ets-1 p51 expression vector. Cells were harvested $48 \mathrm{~h}$ after transfection with $200 \mu \mathrm{l}$ of passive lysis buffer (Promega) and each supernatant was sequentially tested for firefly and renilla luciferase activity (Dual-Luciferase ${ }^{\circledR}$ Reporter Assay System, Promega) using a Centro LB 960 (Berthold, Bad Wildbad, Germany) luminometer. For each expression vector combination and concentration, firefly luciferase activity (pGL-2/3 constructs) was normalised to the renilla activity (pRL-null normalisation vector (Promega)) to correct for variation in the number of transfected cells. Expression of proteins of interest was tested by Western blot analysis.

\section{Western blot analysis}

Total cell lysate proteins were boiled in Laemmli buffer (50 mM Tris $\mathrm{pH} 6.8 ; 2 \% \mathrm{SDS} ; 5 \% \beta-$ mercaptoethanol; $10 \%$ glycerol; $0.1 \%$ bromophenol blue) and resolved by SDS/PAGE. Proteins in gels were transferred to a Hybond ${ }^{\mathrm{TM}}-\mathrm{C}$ Extra membrane (Amersham Biosciences, Piscataway, NJ, USA) and blocked for $1 \mathrm{~h}$ at room temperature in 5\% non-fat milk in PBS solution. The membrane was then incubated with the primary antibody for $1 \mathrm{~h}$ at room temperature in blocking buffer. Ets-1 was detected with the C-20 polyclonal antibody directed 
241 against the C-terminal region or the N-276 polyclonal antibody directed against the N242 terminal region (Santa Cruz Biotechnology ${ }^{\circledR}$, Santa Cruz, CA, USA), Erk-2 with the C-14 243 polyclonal antibody (Santa Cruz Biotechnology ${ }^{\circledR}$ ), cleaved caspase-3 with the 5A1 polyclonal 244 antibody (Cell Signaling Technology ${ }^{\circledR}$, Beverly, MA), c-Jun with the H-79 polyclonal 245 antibody (Santa Cruz Biotechnology ${ }^{\circledR}$ ) and c-Fos with the H-125 polyclonal antibody (Santa 246 Cruz Biotechnology $\left.{ }^{\circledR}\right)$. The washed membrane was then incubated for $1 \mathrm{~h}$ at room 247 temperature with horseradish peroxidase (HRP)-conjugated secondary antibody (Santa Cruz 248 Biotechnology ${ }^{\circledR}$ ) in blocking buffer. Bound antibodies were yisualized using Western 249 Lightning $^{\mathrm{TM}}$ chemiluminescence detection system (Perkin Elmer Life Sciences 250 Biotechnology ${ }^{\circledR}$ ). For quantification of Western blot protein expression, luminescence was 251 recorded using a digital camera with a cooled charge-coupled device (LAS 3000; Fuji) and 252 quantified using the Multi Gauge V3.0 image analysis software (Fuji Film). Reprobing was 253 performed using the Re-Blot Plus Strong Antibody Stripping solution according to the 254 manufacturer's instructions (Millipore, Temecula, CA).

256 Electrophoretic mobility shift assay (EMSA)

257 Double-stranded synthetic oligonucleotides corresponding to the WT and EBS mutant of the 258 human stromelysin-1 (-223/-193) promoter region were end-labelled using T4 polynucleotide 259 kinase and $\left[\gamma_{-}{ }^{32} \mathrm{P}\right] \mathrm{ATP}$, and were subsequently purified by electrophoresis on a $20 \%$ 260 polyacrylmamide non-denaturing gel in TBE buffer (90 mM Tris-Borate; $1 \mathrm{mM}$ EDTA). Cell 261 lysates prepared $(30 \mu \mathrm{g})$ from HEK-293 cells transfected with the expression vector, empty or 262 encoding Cp17 fragment, or with recombinant Ets-1 p51 protein $(1 \mu \mathrm{g})$ were incubated with 263 $0.5 \mathrm{ng}$ of labelled probe in $40 \mu \mathrm{l}$ binding reaction buffer $(20 \mathrm{mM}$ Tris $\mathrm{pH} 7.9 ; 80 \mathrm{mM} \mathrm{NaCl}, 1$ mM EDTA; 2 mM DTT, $40 \mu \mathrm{g} / \mathrm{ml}$ poly[dI-dC]poly[dI-dC] (Pharmacia, Piscataway, NJ, USA); $10 \%$ glycerol) for $30 \mathrm{~min}$ on ice. Complexes formed were resolved on a $5 \%$ 
266 polyacrylamide (29:1 acrylamide:bisacrylamide; Euromedex) non-denaturing gel in $0.25 \mathrm{X}$ 267 TBE buffer at room temperature. Gels were dried and autoradiographed at $-80{ }^{\circ} \mathrm{C}$. For probe 268 competition, $400 \mathrm{ng}$ of non-labelled probe (800X) were added to the reaction mixture. For 269 protein competition, cell lysates $(30 \mu \mathrm{g})$ prepared from HEK-293 cells transfected with 270 increasing amounts of the Cp17 expression vector was incubated with recombinant Ets-1 p51 271 protein $(0.5 \mu \mathrm{g})$ with $0.5 \mathrm{ng}$ of WT-labelled probe in the same conditions.

272

\section{Expression and purification of Ets-1 p51 protein}

274 Ets-1 p51 was expressed and purified using the T7-Impact ${ }^{\mathrm{TM}}$ System (new England Biolabs ${ }^{\circledR}$ ) 275 as previously described [17].

\section{RNA extraction and RT-PCR assays}

278 RNA was extracted from HIG-82 cells using TRIzol ${ }^{\circledR}$, according to the manufacturer's 279 instructions (Invitrogen ${ }^{\mathrm{TM}}$ ). Reverse-transcription was performed with random hexameric 280 oligonucleotides with $1 \mu \mathrm{g}$ of cDNA using the RevertAid ${ }^{\mathrm{TM}}$ First Strand cDNA kit 281 (Fermentas, Burlington, Ontario, Canada). PCR reactions were performed with the High 282 Fidelity PCR Master mixture (Roche, Meylan, France) with 500 ng of reverse-transcribed 283 RNAs and with $125 \mathrm{ng}$ of forward and reverse primers for each of four genes: human $\underline{e t s-1}$, 284 5'-ATGAAGGCGGCCGTCGATCTC-3' and 5'-TTGGTCCACTGCCTGTGTAG-3'; gapdh 285 (glyceraldehyde-3-phosphate dehydrogenase), 5'-ATGAGGTCCACCACCCTGTT-3' and 5'286 ATCACTGCCACCCAGAAGAC-3'; gelatinase-B, 5'- CTGGGCAAGGGCGTCGTGGTC287 3' and 5'-CGTGGTGCAGGCGGTGTAGGAG-3'; and $\underline{u P A}$, 5'288 CCATCCCGGTCCATACAGACT-3' and 5'- TCACAGCTTGTGCCAAAATTG-3'. PCRs 289 were run for 35 cycles with $30 \mathrm{~s}$ denaturation at $94^{\circ} \mathrm{C}, 30 \mathrm{~s}$ hybridization at $55^{\circ} \mathrm{C}$ and $30 \mathrm{~s}$ 
290 elongation at $72^{\circ} \mathrm{C}$. Amplified products were analysed on $2 \%$ agarose gels run in $0.5 \mathrm{X}$ TBE 291 buffer and stained with ethidium bromide.

\section{RESULTS}

\section{Ets-1 is a substrate for caspases}

295 To investigate Ets-1 fate during programmed cell death, Jurkat T-leukaemia cells, which 296 endogenously express Ets-1 p51 and Ets-1 p42 isoforms, were treated with the apoptotic 297 inducer staurosporin (Figure 1A). This stress stimulus was found to activate caspase-3 with 298 detection in Western blot of the specific p19 and p17 caspase-3 fragments (Figure 1A, lane 2). 299 This effect was associated with a decrease in Ets-1 levels and generation of three new Ets-1 300 fragments of about 14, 17 and $20 \mathrm{kDa}$ in apparent molecular mass, designated as Cp14, Cp17 301 and Cp20, with Cp17 being the predominant fragment. These fragments were detected using an anti-Ets-1 antibody directed against its DBD located in the C-terminal region. Using an anti-Ets-1 antibody directed against its Pointed domain located in the N-terminal region, the same blot revealed a new Ets-1 fragment of about $36 \mathrm{kDa}$ in apparent molecular mass, 305 designated as Np36 (Figure 1A, lane 2). This suggests that Ets-1 factor was cleaved, leading 306 to generation of three C-terminal and one N-terminal fragments. Furthermore, Ets-1 307 processing was abrogated by the addition of the potent general caspase inhibitor zVAD-FMK 308 to Jurkat cells medium prior to staurosporin treatment (Figure 1A, lanes 3 and 4), 309 demonstrating that caspases are involved in Ets-1 cleavage.

To confirm that caspases are able to process the Ets-1 transcription factor, Jurkat cell 311 extracts were exposed to recombinant active caspase- 3 and analysed by Western blot using 312 the same antibodies as in the previous experiment (Figure 1B). Results showed that 313 recombinant active caspase-3 reduced endogenous Ets-1 levels (Figure 1B, lanes 1 and 2) and 314 produced the same fragments as those generated after staurosporin treatment (compared 
315 Figure 1A, lane 2 and Figure 1B, lane 2), i.e. the Cp14, Cp17 and Cp20 C-terminal and the 316 Np36 N-terminal fragments. These results unequivocally demonstrate that the Ets-1 protein is 317 processed by caspases during apoptosis.

\section{Ets-1 p51, but not Ets-1 p42, is cleaved in vitro by recombinant active caspase-3}

320 To determine if one or both Ets- 1 isoforms constitute caspase- 3 substrates, Ets-1 p51 or Ets-1 321 p42 were exogenously expressed in HEK-293 cells, which do not encode Ets-1. Cell lysates were then exposed to recombinant active caspase-3 (Figure 2A). Western blot analysis revealed that exogenous Ets-1 p51 levels were drastically reduced after incubation with recombinant active caspase-3 (Figure 2A, lanes 3 and 4), whereas exogenous Ets-1 p42 levels were not affected (Figure 2A, lanes 5 and 6). Furthermore, the decrease in Ets-1 p51 intensities was associated with the production of the $\mathrm{Cp} 14, \mathrm{Cp} 17, \mathrm{Cp} 20$ and Np36 fragments

(Figure 2A, lane 4). Thus, Ets-1 p51, but not Ets-1 p42, is a substrate of recombinant active caspase-3 in vitro.

The same experiment was performed using other recombinant active caspases, in 330 particular caspase-3, -6, -7, -8 and -9 (Figure 2B). Results showed that among the tested 331 proteases, the caspase-3 was the only one that cleaved exogenous Ets-1 p51 (Figure 2B, lanes 332 2-7), while Ets-1 p42 was not cleaved by caspase-3 or any other caspase (Figure 2B, lanes 8$33313)$

\section{Ets-1 p51, but not Ets-1 p42, is cleaved in cells undergoing apoptosis}

336 We then checked the consequences of apoptotic signals on the cleavage of Ets-1 p51 and Ets3371 p42 by caspases. Ets-1 p51 and Ets-1 p42 were expressed in HEK-293 cells, in the presence 338 or absence of the apoptotic inducer staurosporin (Figure 3A). Western blot analysis of cell 339 lysates showed that the three C-terminal cleavage fragments were generated in cells 
expressing Ets-1 p51 (Figure 3A, lanes 5 and 6). Furthermore, the incubation of cells with $341 \mathrm{zVAD}-\mathrm{FMK}$ abrogated the production of the cleavage fragments (Figure 3A, lanes 7 and 8). 342 In contrast, the exogenous expression of Ets-1 p42 in HEK-293 cells did not generate any 343 proteolytic fragments (Figure 3A, lanes 9-12). Taken together, these results show that 344 exogenous Ets-1 p51, but not Ets-1 p42, is cleaved by caspases in apoptotic HEK-293 cells. To determine whether the differential caspase cleavage of the two Ets- 1 isoforms could occur in endogenous conditions, apoptosis of Jurkat cells was induced by staurosporin treatment and cell lysates were analysed by Western blot at several time intervals (Figure 3B).

348 Upon induction of apoptosis, the three C-terminal fragments were generated as expected. The level of the Cp20 fragment, detected after $2 \mathrm{~h}$, declined over the $8 \mathrm{~h}$ time course, suggesting that it may be degraded. In contrast, the Cp17 and Cp14 fragments were stable over time. 351 Along with the generation of fragments, Ets-1 p51 levels simultaneously greatly decreased in 352 a time-dependent manner, while Ets-1 p42 levels declined only weakly over the same period. 353 The quantification of Ets-1 isoform levels in three independent experiments (Figure 3C) 354 confirmed that the amount of Ets-1 p51 decreased about $60 \%$ during the $8 \mathrm{~h}$ time course 355 experiment, while Ets-1 p42 level remained unchanged. Furthermore, the quantification of $356 \mathrm{Cp} 17$, the main fragment, showed that it was stable over time (Figure 3C). Incubating cells 357 with zVAD-FMK prior to staurosporin treatment abrogated the reduction of Ets-1 p51 levels 358 (Figure 3B, lane 5 and Figure $3 \mathrm{C}$ ) as well as the formation of cleavage fragments (Figure 3B, 359 lane 5). Our results demonstrate that in Jurkat cells undergoing apoptosis, Ets-1 p51, unlike 360 Ets-1 p42, is down-regulated. Taken together, this suggests that caspase cleavage of Ets-1 p51 361 during apoptosis contributes to the efficient degradation of Ets-1 and generates fragments of 362 Ets-1. 
365 The cleavage motif for caspases is a sequence of four amino acids, numbered P4-P1, which is 366 processed after the invariant $\mathrm{P} 1$ aspartic acid residue. The Asp-X-X-Asp is a cleavage motif 367 present in many caspase-3 substrates $[36,37]$. The amino-acid sequence of human Ets-1 p51 368 has three putative cleavage sites for caspases in the exon VII-encoded region, DSCD ${ }^{262}$, a 369 double site $\mathrm{DSFD}^{287} \mathrm{SED}^{290}$, and $\mathrm{DRAD}^{313}$ (Figure 4Aa). The position of these sites is 370 consistent with the generation of three C-terminal fragments of 20, 17 and $14 \mathrm{kDa}$ (Figure $3714 \mathrm{Ab}$ ). In addition, the location of these sites in the exon VII-encoded region is consistent with 372 the resistance of Ets-1 p42 to caspase cleavage.

373 To determine whether Ets-1 p51 is cleaved by caspases at these sites, site-directed 374 mutagenesis was performed: (i) on the first putative caspase site in which $\mathrm{Asp}^{262}$ was 375 substituted by Asn (D1N); (ii) on the two first putative caspase sites in which Asp ${ }^{262}$ and a 376 double sites $\mathrm{Asp}^{287} / \mathrm{Asp}^{290}$ were mutated to Asn (D3N) and (iii) on all the caspase sites of the exon VII-encoded region (D4N) (Figure 4Ac).

After the exogenous expression of WT or mutant (D1N, D3N, D4N) Ets-1 p51 in HEK-293 cells, lysates were exposed to recombinant, active caspase-3 and analysed by 380 Western blot (Figure 4B). In contrast to WT Ets-1 p51 (Figure 4B, lane 2), all three mutants 381 were resistant to caspase-3 cleavage (Figure 4B, lanes 4, 6 and 8). Thus, DSCD $^{262}$ was an 382 essential site for in vitro caspase- 3 cleavage because its mutation abrogates the processing at 383 the other sites.

Second, we assessed the role of these sites for Ets-1 p51 processing in MDCK cells 385 undergoing apoptosis. MDCK cells exogenously expressing WT or mutant Ets-1 p51 were 386 incubated with or without anisomycin and cell lysates were analysed by Western blot (Figure 387 4C). As expected, WT Ets-1 p51 generated the C-terminal fragments with Cp17 388 predominating (Figure 4C, lane 2). It is noteworthy that Ets-1 fragments occurred in the 389 absence of any apoptotic inducer; this may be due to stress caused by transfection conditions 
390 (Figure 4C, lane 3), as previously reported for MDCK cells [38, 39]. The D1N mutant 391 abrogated Cp20 generation, while Cp17 and Cp14 were still detectable (Figure 4C, lane 4), 392 demonstrating that $\mathrm{Cp} 20$ was generated through cleavage on $\mathrm{Asp}^{262}$ amino acid. The D3N 393 mutant abrogated generation of all the fragments (Figure 4C, lane 6), demonstrating that 394 cleavage on $\mathrm{DSFD}^{287} \mathrm{SED}^{290}$ is necessary for generation of the main Cp17 fragment and the 395 secondary Cp14 fragment. Taken together, these results demonstrate that Ets-1 p51 was 396 cleaved at caspase sites with aspartic acid located at positions 262, 290 and 313, allowing 397 generation of the three C-terminal fragments $\mathrm{Cp} 20, \mathrm{Cp} 17$ and $\mathrm{Cp} 14$, respectively. In addition, $398 \operatorname{DSCD}^{262}$ and DSFDSED ${ }^{290}$ sites are critical for cleavage in vitro and during apoptosis, 399 respectively.

400

401 Cp17 binds to the EBS palindrome of the stromelysin-1 promoter and competes with $402 \quad$ Ets-1 p51 for binding

403 Caspase cleavage during apoptosis generated $\mathrm{Cp} 17$, the major C-terminal fragment that 404 conserves the DNA-binding domain surrounded by the two inhibitory domains (Figure 5A). 405 This suggests that Cp17 would be able to bind DNA as Ets-1 p51 does. To test this 406 hypothesis, the nucleotide sequence of Cp17, which codes for amino acids 291-441 of Ets-1 407 p51 (Figure 5A), was cloned into a eukaryotic expression vector and used in an 408 electrophoretic mobility shift assay (EMSA).

409 Assays were carried out using: (i) lysates from HEK-293 cells transfected with empty 410 vector, (ii) lysates from HEK-293 cells transfected with Cp17 expression vector or (iii) Ets-1 411 p51 recombinant protein. Proteins were incubated with $30-\mathrm{mer}{ }^{32} \mathrm{P}$-labeled DNA probes 412 containing WT or mutant EBS palindromes of the stromelysin-1 promoter (Figure 5B). 413 Results showed that Ets-1 p51 formed a complex with the WT promoter (arrow 3; Figure 5B, 414 lanes 5). This may correspond to a ternary complex with two protein molecules bound to the 
415 WT EBS palindrome, as previously reported [17]. Two complexes were detected with lysates

416 from cells transfected with $\mathrm{Cp} 17$. The slower migrating band was probably a ternary complex

417 (arrow 3'; Figure 5B, lane 9) because we detected a smaller binding species, which may 418 correspond to a binary complex formed by one protein molecule bound to the stromelysin-1 419 promoter (arrow 2'; Figure 5B, lane 9). Mutation of the EBS palindrome prevented both Ets-1 420 p51 and Cp17 forming DNA/protein complexes (Figure 5B, lanes 6 and 10). These complexes 421 were disrupted by an excess of non-labelled WT DNA probe (Figure 5B, lanes 7 and 11), but 422 not by an excess of non-labelled double-mutant DNA probe (Figure 5B, lanes 8 and 12), 423 confirming that these complexes were specific to the EBS palindrome.

Next, we assessed the ability of Cp17 to compete with Ets-1 p51 for DNA binding. 425 EMSA experiments were carried out using a 30 -mer ${ }^{32}$ P-labelled WT DNA probe and 426 increasing concentrations of Cp17 exogenously expressed in HEK-293 cells, with or without 427 recombinant Ets-1 p51 (Figure 5C). Results showed that the Ets-1 p51/ DNA/Ets-1 p51 ternary complex (Figure 5C, arrow 3, lane 6) was disrupted in the presence of Cp17 (Figure 5C, lanes 7-9). This disruption was accompanied by the formation of intermediate complexes 430 (indicated by arrow i) with lower molecular masses, which may be composed of both Ets-1 p51 and Cp17. Thus, the Cp17 cleavage fragment competes with Ets-1 p51 for binding to the EBS palindrome in the stromelysin-1 promoter.

\section{Cp17 cleavage fragment is a dominant negative for Ets-1 p51 transactivation}

435 The caspase cleavage within the exon VII-encoded region separates the N-terminal 436 transactivation domain from the C-terminal DNA binding domain. This suggests that Cp17 would be a dominant negative for Ets-1 p51-mediated transcription. To test this hypothesis,

438 luciferase transactivation assays were performed with the WT or EBS mutant stromelysin-1 439 promoter using increasing concentrations of Cp17 with or without Ets-1 p51 (Figure 6A). 
440 Cp17 was unable to substantially activate the stromelysin-1 promoter on its own (Figure 6A, 441 upper part, lanes 1-4). Nevertheless, it repressed in a dose-dependent manner the Ets-1 p51442 induced activation of the WT promoter (Figure 6A, upper part, lanes 5-8), with more than $44360 \%$ suppression when present at a 1:1 ratio with Ets-1 p51 (Figure 6A, lane 7). This was 444 mediated through the EBS palindrome because mutation of both EBS abrogated any Cp17 445 effects (Figure 6A, middle part). Protein expression was confirmed by Western blot for Ets-1 446 p51, Cp17, and Erk-2 as a loading control (Figure 6A, lower part). Thus, Cp17 acts as a 447 dominant negative for Ets-1 p51 transactivation of the stromelysin- 1 promoter mediated 448 through the EBS palindrome.

Second, we examined the effect of Cp17 on the collagenase-1 matrix 450 metalloproteinase promoter, another Ets-1 target gene, which is synergistically activated by 451 Ets-1 p51 and c-Jun/c-Fos (AP-1) complex, through the TPA (12-O-tetradecanoylphorbol-13acetate) Oncogene Response Unit (TORU), composed of an EBS adjacent to an AP-1 site [40]. Luciferase transactivation assays were performed with collagenase-1 promoter (WT or EBS/AP-1 mutant) using increasing concentrations of Cp17 with or without Ets-1 p51 and the 455 c-Jun/c-Fos complex (Figure 6B). Cp17 repressed, in a dose-dependent manner, the 456 synergistic activation of the collagenase- 1 promoter induced by Ets-1 p51 and the c-Jun/c-Fos 457 complex (Figure 6B, upper part). This was mediated through the TORU, since its mutation 458 abrogated any Cp17 effects (Figure 6B, middle part). Thus, Cp17 acts also as a dominant 459 negative for Ets-1 p51 transactivation of the collagenase-1 promoter mediated through the 460 TORU.

We then checked the transcriptional response of the N-terminal Np36 fragment. The nucleotide sequence, which codes for amino acids 1-262 of Ets-1 p51, was cloned in a 463 eukaryotic expression vector and used in luciferase transactivation assays. Results showed 464 that Np36 does not inhibit the Ets-1 p51-induced transcriptional activation of the stromelysin- 
465

466

467

468

469

470

471

472

473

474

475

476

477

478

479

480

481

482

483

484

485

486

487

488

489

1 and collagenase- 1 promoters, due to the absence of the DBD domain (Figure 6D). Thus, in contrast to $\mathrm{Cp} 17$ fragment, the Np36 fragment is not able to inhibit the transcriptional activity of Ets-1 p51.

\section{Cp17 decreases the Ets-1 p51 target genes expression}

Given the dominant-negative function of $\mathrm{Cp} 17$, we explored its effect on the expression of endogenous Ets-1 p51 target genes. To this aim, we performed RT-PCR analysis on HIG-82 rabbit synovial fibroblasts, which endogenously express the Ets-1 protein and represent a good model to study the transcriptional regulation of Ets-1 target genes [41]. We transfected these cells with an empty vector, with a human Ets-1 p51 expression vector or with both human Ets-1 p51 and Cp17 expression vectors. Results showed that the overexpression of human Ets-1 p51 alone induced an increase in the mRNA levels of well-known Ets-1 target genes, such as gelatinase- $B$ and $u P A$ (Figure 7; compare lane 2 and 3), indicating that Ets-1 p51 up-regulated the expression of these genes. However, the overexpression of both Ets-1 p51 and Cp17 decreased the mRNA levels of these target genes (Figure 7; lane 4). This shows that Cp17 inhibits the expression of endogenous Ets-1 target genes, confirming its dominantnegative function on Ets-1 p51.

\section{DISCUSSION}

Although previous studies have described the down-regulation of the Ets-1 p51 protein in cells undergoing apoptosis $[31,32]$, the molecular mechanism underlying this effect was not known. In this study, we demonstrated that the down-regulation of Ets-1 p51 protein in Jurkat $\mathrm{T}$ cells undergoing apoptosis is a consequence of its caspase-dependent cleavage. Caspase cleavage generated three C-terminal fragments, Cp14, Cp17 and Cp20, and one detectable Nterminal fragment, Np36. Screening the amino acid sequence of Ets-1 for putative caspase 
490

491

cleavage sites made possible to identify three consensual sites (DXXD) located in the exon VII-encoded region: $\mathrm{DSCD}^{262}$, a double site $\mathrm{DSFD}^{287} \mathrm{SED}^{290}$ and $\mathrm{DRAD}^{313}$. Mutational analysis indicated that Ets-1 p51 processing occurs at these sites, thus generating the Cp20, Cp17 and Cp14 fragments, respectively. Cp17 was the major fragment generated during apoptosis, suggesting that $\mathrm{DSFD}^{287} \mathrm{SED}^{290}$ is the main cleavage site. The $\mathrm{N}$-terminal Np36 fragment detected during apoptosis may be the N-terminal counterpart of the C-terminal Cp20 fragment generated through cleavage at the $\mathrm{DSCD}^{262}$ site. Consistent with the location of the caspase sites in the alternate exon VII-encoded region, Ets-1 p42 was not processed by caspases in in vitro cleavage experiments, nor during apoptosis.

The exon VII-encoded region of Ets-1 is a regulatory domain described as (i) a regulator of DNA-binding [16, 17, 41], (ii) a mediator of protein-protein interactions [42] and (iii) a target of calcium-mediated phosphorylation $[43,44]$. The cleavage of Ets-1 p51 and not Ets-1 p42 allocates a new function to the exon VII-encoded region, thus expanding on the functional differences between the two Ets-1 isoforms.

Cleavage of Ets-1 p51 in the exon VII-encoded region separate the transactivation domain - crucial for transcriptional activity - from the rest of the molecule but leave the DNA-binding domain intact. Therefore, C-terminal Ets-1 fragments containing the DBD should be able to bind to Ets-1 p51 target promoters without activating transcription, suggesting that they have a dominant-negative function. Our results confirmed this hypothesis for the major cleavage product, Cp17. Its DNA-binding and transcriptional properties were assessed on the EBS palindrome of the stromelysin-1 promoter, which has been shown to be an important target gene for Ets-1 and is involved in the process of tumour invasion and metastasis [45]. Our results demonstrated that Cp17 competes with Ets-1 p51 for binding to the EBS palindrome of the stromelysin-1 promoter, demonstrating its dominant-negative effect on Ets-1 p51 binding. This competition involves the formation of an intermediate 
515 complex, suggesting that both proteins interact with each other on the EBS palindrome of the 516 stromelysin-1 promoter. Cp17 forms also a binary complex with the DNA, which may 517 represent a transient complex facilitating the binding of a second $\mathrm{Cp} 17$ molecule to form a 518 ternary complex. This is consistent with previous work that showed that deleting the N519 terminal region of Ets-1 p51 spanning from amino acids 1-300 does not alter the binding 520 stoichiometry for the EBS palindrome found in the stromelysin-1 promoter $[17,18]$. It is 521 noteworthy that we did not detect any binary complexes involving Ets-1 p51 because full522 length Ets-1 p51 more readily forms ternary complexes. Furthermore, Cp17 inhibited Ets-1 523 p51 transactivation of the stromelysin-1 promoter. This effect may be the result of Cp17 524 binding to the palindromic EBS, which then becomes inaccessible to Ets-1 p51. Cp17 also 525 repressed the Ets-1 p51-mediated transactivation of the collagenase-1 promoter. This may 526 result from the ability of $\mathrm{Cp} 17$ to replace Ets-1 p51 in the interaction with the AP-1 complex 527 (c-Fos/c-Jun), required for combinatorial regulation. This is supported by the fact that the 528 interaction of Ets-1 p51 with the AP-1 complex is mediated through the DBD domain, which 529 is conserved in $\mathrm{Cp} 17$ [12]. The N-terminal Np36 fragment did not have any effect on the Ets5301 p51-induced transcriptional activation of either the stromelysin-1 or the collagenase-1 531 promoters. This is consistent with the inability of Np36 to bind DNA because it lacks the 532 DBD domain. This confirms that the dominant-negative effect of Cp17 effectively results 533 from its binding to the Ets-1 p51 target promoters. Finally, Cp17 decreased Ets-1-induced 534 expression of $u P A$ and gelatinase- $B$, two well-known target genes of Ets-1, confirming the 535 dominant-negative function of Cp17 on Ets-1 p51.

536 Ets-1 functions have been largely studied through the use of artificial dominant537 negative constructs made up of the DBD domain of the molecule $[23,46]$. These constructs 538 have helped to demonstrate, for instance, the involvement of Ets-1 in tumorigenesis and 539 angiogenesis [46-48]. The Cp17 fragment represents a natural dominant negative generated 
540 by proteolytic cleavage, able to inhibit the transactivation response induced by the full-length 541 protein. However, in contrast to artificial DBD constructs, Cp17 possesses the two inhibitory 542 domains flanking the DBD. Cp17 is thereby more specific, particularly for promoters that 543 have either palindromic EBS or adjacent DNA elements and that can be activated only by 544 overriding Ets-1 autoinhibition.

Along the same lines, we recently demonstrated that a novel Ets-1 isoform, p27, which

546 lacks the Pointed and the transactivation domains but conserves the DBD flanked by the two 547 inhibitory domains, also acts as a dominant negative of Ets-1 p51 [33]. The overexpression of 548 this novel isoform in invasive mammary carcinoma cells represses proliferation, 549 transformation and invasion, and reduces the growth of tumour xenografts in nude mice. The 550 splice variant Ets-1 p27 and the Ets-1 p51 cleavage product Cp17, both of which possess the 551 DBD and the inhibitory domains, represent natural dominant negatives of the full-length 552 protein generated by two different mechanisms.

553 The caspase-mediated generation of dominant-negative fragments has also been 554 described for several other transcription factors. For instance, NF-kB p65/RelA subunit [8] 555 and SRF [6] provide two examples of transcription factors in which caspase cleavage leads to 556 separation of the transactivation domain from the DNA binding domain. These truncated 557 proteins are transcriptionally inactive and also act as dominant-negative inhibitors [6, 8].

558 Since some studies have shown that Ets-1 plays a role in apoptosis through the control 559 of gene expression critical to this process, we can assume that down-regulation of Ets-1 p51 560 during apoptosis could prevent this transcriptional program. Following this line of reasoning, 561 the dominant-negative function of Cp17 may provide an additional mechanism to amplify the 562 cell death process by inhibiting the Ets-1 p51-mediated expression of anti-apoptotic proteins.

563 This would be consistent with a previous study demonstrating that artificial Ets-dominant 564 negatives suppress Ets transcriptional activity and induce programmed cell death — mediated 
565 by lower levels of c-myc expression - in thyroid carcinoma cell lines [23]. Although the 566 anti-apoptotic target genes of Ets-1 p51 and their promoters are currently not well 567 characterised, it would interesting to assess the dominant-negative properties of $\mathrm{Cp} 17$ on 568 these target genes. In addition, we demonstrated that caspase cleavage targets Ets-1 p51 569 without affecting the Ets-1 p42 isoform. Consequently, during apoptosis, the ratio between 570 the two isoforms is modified in favour of the Ets-1 p42 isoform. Interestingly, it has been 571 shown that, compared to Ets-1 p51, Ets-1 p42 is preferentially associated with the induction 572 of apoptosis. Therefore, the modification of the ratio between the two isoforms may be a 573 mechanism favouring cell death through the specific preservation of the pro-apoptotic 574 isoform.

575 Taken together, out data suggest a novel mechanism of Ets-1 p51 regulation through 576 caspase-mediated cleavage and generation of a dominant-negative fragment, which may play 577 active role during apoptosis.

\section{ACKNOWLEDGMENTS}

580 We warmly thank Dr M. Duterque-Coquillaud for generously providing the human 581 collagenase-1 promoter as well as the pSG5-c-Fos, and pSG5-c-Jun vectors and Dr D. Monté 582 for providing the pcDNA3-Flag vector. We are grateful to I. Roland for technical assistance.

\section{FUNDING}

585 This work was supported by the Centre National de la Recherche Scientifique (CNRS) and by 586 grants from the Ligue contre le Cancer-Comité Pas-de-Calais, the Fondation pour la 587 Recherche Médicale-Comité Nord-Pas-de-Calais (to M.A. and D.T.), the Association pour la 588 Recherche sur le Cancer and Agence Nationale de la Recherche-Young Investigator Program 589 (to D.T.). A Ph.D. fellowship was provided to S.C. by the CNRS and the Conseil Régional 
Nord-Pas-de-Calais (BDI: Bourse de Docteur-Ingénieur), to G.L. by the Ligue Nationale

591 contre le Cancer and to C.L. by the French Ministère de la Recherche et de 1'Enseignement

592 Supérieur.

593

594

\section{REFERENCES}

5951 Song, Z. and Steller, H. (1999) Death by design: mechanism and control of apoptosis.

600

601

602

603

604

605

606

607

608

609

610

611

612

613

614

615

616

617

618

619

620

621

622

623

624

625

626

627

628

629

630

631

632

7 Gianni, M. and de The, H. (1999) In acute promyelocytic leukemia NB4 cells, the synthetic retinoid CD437 induces contemporaneously apoptosis, a caspase-3-mediated degradation of PML/RARalpha protein and the PML retargeting on PML-nuclear bodies. Leukemia 13, 739-749

8 Levkau, B., Scatena, M., Giachelli, C. M., Ross, R. and Raines, E. W. (1999) Apoptosis overrides survival signals through a caspase-mediated dominant-negative NF-kappa B loop. Nat Cell Biol 1, 227-233

9 Sarrazin, S., Bonod-Bidaud, C., Remy, P., Mehlen, P. and Morle, F. (2002) Caspase cleavage of the transcription factor FLI-1 during preB leukemic cell death. Biochim Biophys Acta 1592, 123-127

10 Graves, B. J. and Petersen, J. M. (1998) Specificity within the ets family of transcription factors. Adv Cancer Res 75, 1-55

11 Sharrocks, A. D. (2001) The ETS-domain transcription factor family. Nat Rev Mol Cell Biol 2, 827-837

12 Dittmer, J. (2003) The biology of the Ets1 proto-oncogene. Mol Cancer 2, 29

13 Redlich, K., Kiener, H. P., Schett, G., Tohidast-Akrad, M., Selzer, E., Radda, I., Stummvoll, G. H., Steiner, C. W., Groger, M., Bitzan, P., Zenz, P., Smolen, J. S. and Steiner, G. (2001) Overexpression of transcription factor Ets-1 in rheumatoid arthritis synovial membrane: regulation of expression and activation by interleukin-1 and tumor necrosis factor alpha. Arthritis Rheum 44, 266-274

14 Raffetseder, U., Wernert, N., Ostendorf, T., van Roeyen, C., Rauen, T., Behrens, P., Floege, J. and Mertens, P. R. (2004) Mesangial cell expression of proto-oncogene Ets1 during progression of mesangioproliferative glomerulonephritis. Kidney Int 66, 622632 
15 Koizumi, S., Fisher, R. J., Fujiwara, S., Jorcyk, C., Bhat, N. K., Seth, A. and Papas, T.

634

635

636

637

638

639

640

641

642

643

644

645

646

647

648

649

650

651

652

653

654

655

656

657

658

659

660

661

662

663

664

665

666

667

668

669

670

671

672

673

674

675

676

677

678

679

680

681

S. (1990) Isoforms of the human ets-1 protein: generation by alternative splicing and differential phosphorylation. Oncogene 5, 675-681

16 Fisher, R. J., Fivash, M., Casas-Finet, J., Erickson, J. W., Kondoh, A., Bladen, S. V., Fisher, C., Watson, D. K. and Papas, T. (1994) Real-time DNA binding measurements of the ETS1 recombinant oncoproteins reveal significant kinetic differences between the p42 and p51 isoforms. Protein Sci 3, 257-266

17 Baillat, D., Begue, A., Stehelin, D. and Aumercier, M. (2002) ETS-1 transcription factor binds cooperatively to the palindromic head to head ETS-binding sites of the stromelysin-1 promoter by counteracting autoinhibition. J Biol Chem 277, 2938629398

18 Leprivier, G., Baillat, D., Begue, A., Hartmann, B. and Aumercier, M. (2009) Ets-1 p51 and p42 isoforms differentially modulate Stromelysin- 1 promoter according to induced DNA bend orientation. Nucleic Acids Res

19 Lee, G. M., Donaldson, L. W., Pufall, M. A., Kang, H. S., Pot, I., Graves, B. J. and McIntosh, L. P. (2005) The structural and dynamic basis of Ets-1 DNA binding autoinhibition. J Biol Chem 280, 7088-7099

20 Pufall, M. A. and Graves, B. J. (2002) Autoinhibitory domains: modular effectors of cellular regulation. Annu Rev Cell Dev Biol 18, 421-462

21 Wasylyk, C., Gutman, A., Nicholson, R. and Wasylyk, B. (1991) The c-Ets oncoprotein activates the stromelysin promoter through the same elements as several non-nuclear oncoproteins. Embo J 10, 1127-1134

22 Baillat, D., Laitem, C., Leprivier, G., Margerin, C. and Aumercier, M. (2009) Ets-1 binds cooperatively to the palindromic Ets-binding sites in the p53 promoter. Biochem Biophys Res Commun 378, 213-217

23 de Nigris, F., Mega, T., Berger, N., Barone, M. V., Santoro, M., Viglietto, G., Verde, P. and Fusco, A. (2001) Induction of ETS-1 and ETS-2 transcription factors is required for thyroid cell transformation. Cancer Res 61, 2267-2275

24 Li, R., Pei, H. and Papas, T. (1999) The p42 variant of ETS1 protein rescues defective Fas-induced apoptosis in colon carcinoma cells. Proc Natl Acad Sci U S A 96, 38763881

25 Xu, D., Wilson, T. J., Chan, D., De Luca, E., Zhou, J., Hertzog, P. J. and Kola, I. (2002) Ets1 is required for p53 transcriptional activity in UV-induced apoptosis in embryonic stem cells. Embo J 21, 4081-4093

26 Teruyama, K., Abe, M., Nakano, T., Iwasaka-Yagi, C., Takahashi, S., Yamada, S. and Sato, Y. (2001) Role of transcription factor Ets-1 in the apoptosis of human vascular endothelial cells. J Cell Physiol 188, 243-252

27 Zhang, C., Kavurma, M. M., Lai, A. and Khachigian, L. M. (2003) Ets-1 protects vascular smooth muscle cells from undergoing apoptosis by activating p21WAF1/Cip1: ETS-1 regulates basal and and inducible p21WAF1/Cip: ETS-1 regulates basal and inducible p21WAF1/Cip1 transcription via distinct cis-acting elements in the p21WAF/Cip1 promoter. J Biol Chem 278, 27903-27909

28 Nakazawa, Y., Suzuki, M., Manabe, N., Yamada, T., Kihara-Negishi, F., Sakurai, T., Tenen, D. G., Iwama, A., Mochizuki, M. and Oikawa, T. (2007) Cooperative interaction between ETS1 and GFI1 transcription factors in the repression of Bax gene expression. Oncogene 26, 3541-3550

29 Pei, H., Li, C., Adereth, Y., Hsu, T., Watson, D. K. and Li, R. (2005) Caspase-1 is a direct target gene of ETS1 and plays a role in ETS1-induced apoptosis. Cancer Res 65 , 7205-7213 
$68230 \quad$ Huang, C. C., Papas, T. S. and Bhat, N. K. (1997) A variant form of ETS1 induces

683

684

685

686

687

688

689

690

691

692

693

694

695

696

697

698

699

700

701

702

703

704

705

706

707

708

709

710

711

712

713

714

715

716

717

718

719

720

721

722

723

724

725

726

727

728

729

730 apoptosis in human colon cancer cells. Oncogene 15, 851-856

$31 \mathrm{Yu}, \mathrm{Z}$. and Shah, D. M. (2007) Curcumin down-regulates Ets-1 and Bcl-2 expression in human endometrial carcinoma HEC-1-A cells. Gynecol Oncol 106, 541-548

32 Koskela, K. and Lassila, O. (2003) Single-cell analysis of Ets-1 transcription factor expression during lymphocyte activation and apoptosis. Scand J Immunol 57, 56-61

33 Laitem, C., Leprivier, G., Choul-Li, S., Begue, A., Monte, D., Larsimont, D., Dumont, P., Duterque-Coquillaud, M. and Aumercier, M. (2009) Ets-1 p27: a novel Ets-1 isoform with dominant-negative effects on the transcriptional properties and the subcellular localization of Ets-1 p51. Oncogene 28, 2087-2099

34 Tulasne, D., Paumelle, R., Weidner, K. M., Vandenbunder, B. and Fafeur, V. (1999) The multisubstrate docking site of the MET receptor is dispensable for MET-mediated RAS signaling and cell scattering. Mol Biol Cell 10, 551-565

35 Stennicke, H. R. and Salvesen, G. S. (1999) Caspases: preparation and characterization. Methods 17, 313-319

36 Talanian, R. V., Quinlan, C., Trautz, S., Hackett, M. C., Mankovich, J. A., Banach, D., Ghayur, T., Brady, K. D. and Wong, W. W. (1997) Substrate specificities of caspase family proteases. J Biol Chem 272, 9677-9682

37 Thornberry, N. A., Rano, T. A., Peterson, E. P., Rasper, D. M., Timkey, T., GarciaCalvo, M., Houtzager, V. M., Nordstrom, P. A., Roy, S., Vaillancourt, J. P., Chapman, K. T. and Nicholson, D. W. (1997) A combinatorial approach defines specificities of members of the caspase family and granzyme B. Functional relationships established for key mediators of apoptosis. J Biol Chem 272, 17907-17911

38 Foveau, B., Leroy, C., Ancot, F., Deheuninck, J., Ji, Z., Fafeur, V. and Tulasne, D. (2007) Amplification of apoptosis through sequential caspase cleavage of the MET tyrosine kinase receptor. Cell Death Differ 14, 752-764

39 Tulasne, D., Deheuninck, J., Lourenco, F. C., Lamballe, F., Ji, Z., Leroy, C., Puchois, E., Moumen, A., Maina, F., Mehlen, P. and Fafeur, V. (2004) Proapoptotic function of the MET tyrosine kinase receptor through caspase cleavage. Mol Cell Biol 24, 1032810339

40 Westermarck, J., Seth, A. and Kahari, V. M. (1997) Differential regulation of interstitial collagenase (MMP-1) gene expression by ETS transcription factors. Oncogene 14, 2651-2660

41 Baillat, D., Leprivier, G., Regnier, D., Vintonenko, N., Begue, A., Stehelin, D. and Aumercier, M. (2006) Stromelysin-1 expression is activated in vivo by Ets-1 through palindromic head-to-head Ets binding sites present in the promoter. Oncogene 25, 5764-5776

42 Kim, W. Y., Sieweke, M., Ogawa, E., Wee, H. J., Englmeier, U., Graf, T. and Ito, Y. (1999) Mutual activation of Ets-1 and AML1 DNA binding by direct interaction of their autoinhibitory domains. Embo J 18, 1609-1620

43 Cowley, D. O. and Graves, B. J. (2000) Phosphorylation represses Ets-1 DNA binding by reinforcing autoinhibition. Genes Dev 14, 366-376

44 Rabault, B. and Ghysdael, J. (1994) Calcium-induced phosphorylation of ETS1 inhibits its specific DNA binding activity. J Biol Chem 269, 28143-28151

45 Nelson, A. R., Fingleton, B., Rothenberg, M. L. and Matrisian, L. M. (2000) Matrix metalloproteinases: biologic activity and clinical implications. J Clin Oncol 18, 1135 1149

46 Kita, D., Takino, T., Nakada, M., Takahashi, T., Yamashita, J. and Sato, H. (2001) Expression of dominant-negative form of Ets-1 suppresses fibronectin-stimulated cell 


\section{Figure 2}

adhesion and migration through down-regulation of integrin alpha5 expression in U251 glioma cell line. Cancer Res 61, 7985-7991

47 Mattot, V., Vercamer, C., Soncin, F., Calmels, T., Huguet, C., Fafeur, V. and Vandenbunder, B. (2000) Constitutive expression of the DNA-binding domain of Ets1 increases endothelial cell adhesion and stimulates their organization into capillary-like structures. Oncogene 19, 762-772

48 Pourtier-Manzanedo, A., Vercamer, C., Van Belle, E., Mattot, V., Mouquet, F. and Vandenbunder, B. (2003) Expression of an Ets-1 dominant-negative mutant perturbs normal and tumor angiogenesis in a mouse ear model. Oncogene 22, 1795-1806

\section{FIGURE LEGENDS}

\section{Figure 1 Caspase cleavage of Ets-1}

(A) Cleavage of Ets-1 in Jurkat cells undergoing apoptosis. Jurkat cells were treated with staurosporin $(1 \mu \mathrm{M})$ for $4 \mathrm{~h}$ (lanes 2 and 4 ) or left untreated (lanes 1 and 3 ), in the presence (lanes 3 and 4) or in the absence (lanes 1 and 2) of zVAD-FMK (zVAD; $20 \mu \mathrm{M}$ ). NS, nonspecific band. (B) In vitro cleavage of Ets-1 by recombinant active caspase-3. Total cell lysates were incubated in the absence (lane 1) or in the presence (lane 2) of recombinant active caspase-3 $(0.17 \mu \mathrm{M})$ for $4 \mathrm{~h}$ at $37^{\circ} \mathrm{C}$. (A and $\left.\mathbf{B}\right)$ Cell lysates (30 $\mu \mathrm{g}$ total proteins) were analysed by Western blot using an anti-Ets-1 (C-20) directed against the DBD located in the C-terminal region. The membrane was stripped and reprobed sequentially first with an antiEts-1 (N-276) antibody directed against its pointed domain located in the N-terminal region, then with an anti-cleaved caspase-3 antibody and, finally, with an anti-Erk-2 antibody as a loading control. Arrows indicate cleavage fragments. Molecular mass, indicated on the left of each panel, is given in $\mathrm{kDa}$.

(A) In vitro cleavage of Ets-1 isoforms by recombinant active caspase-3. pcDNA3 expression 
761 lysates were incubated in the absence (lanes 1,3 and 5) or in the presence (lanes 2, 4 and 6) of 762 recombinant active caspase-3 $(0.17 \mu \mathrm{M})$ for $4 \mathrm{~h}$ at $37^{\circ} \mathrm{C}$. (B) In vitro cleavage of Ets-1 763 isoforms by a set of recombinant active caspases. pcDNA3 expression vectors without insert 764 (lane 1), encoding Ets-1 p51 (lanes 2-7) or Ets-1 p42 (lanes 8-13) were transfected in HEK765293 cells and incubated with recombinant active caspase-3 (lanes 3 and 9), -6 (lanes 4 and 766 10), -7 (lanes 5 and 11), -8 (lanes 6 and 12) or -9 (lanes 7 and 13). (A and B) Cell lysates (30 $767 \mu \mathrm{g}$ total proteins) were analysed by Western blot using an anti-Ets-1 (C-20) antibody directed 768 against its C-terminal region and an anti-Ets-1 (N-276) antibody directed against its N769 terminal region. Arrows indicate cleavage fragments. Molecular mass, indicated on the left of 770 each panel, is given in $\mathrm{kDa}$.

771

772 Figure 3 Ets-1 p51, but not Ets-1 p42, is cleaved in HEK-293 and Jurkat cells 773 undergoing apoptosis

774 (A) Cleavage of transfected Ets-1 isoforms in HEK-293 cells undergoing apoptosis. pcDNA3 775 expression vectors without insert (control; lanes 1-4), encoding Ets-1 p51 (lanes 5-8) or Ets-1 776 p42 (lanes 9-12) were transfected in HEK-293 cells. After 24 h, cells, previously incubated 777 with (lanes 3-4, 7-8 and 11-12) or without (lanes 1-2, 5-6 and 9-10) zVAD-FMK (zVAD; 20 $778 \mu \mathrm{M})$, were treated with staurosporin $(10 \mu \mathrm{M})$ (lanes 2, 4, 6, 8, 10 and 12) or left untreated 779 (lanes 1, 3, 5, 7, 9 and 11) for $8 \mathrm{~h}$. Cell lysates (30 $\mu \mathrm{g}$ total proteins) were then analysed by 780 Western blot using an anti-Ets-1 (C-20) antibody and an anti-Erk-2 antibody as a loading 781 control. (B) Cleavage of Ets-1 isoforms in Jurkat cells undergoing apoptosis. Jurkat cells, 782 previously incubated with (lane 5) or without (lanes 1-4) zVAD-FMK (zVAD; $20 \mu \mathrm{M})$, were 783 treated with staurosporin $(1 \mu \mathrm{M})$ for the indicated time. Cells were then lysed and analysed by

784 Western blot using an anti-Ets-1 (C-20) antibody. The membrane was stripped and reprobed 785 sequentially using an anti-cleaved caspase-3 antibody and then an anti-Erk-2 antibody as a 
786 loading control. NS, non-specific band. (C) Luminescence from the Western blot was 787 recorded with a CCD camera and the expression levels of the Ets-1 isoforms and the Cp17 788 fragment were quantified. The percentage of expression was calculated using the signal 789 intensity for Ets- 1 p51 at $\mathrm{t}=0 \mathrm{~h}$ as the reference $(\mathrm{n}=3$; error bars indicate S.D.).

\section{Figure 4 Identification of the caspase cleavage sites in Ets-1 p51 processing}

792 (A, a) Schematic representation of Ets-1 p51 and Ets-1 p42 proteins, showing the putative 793 caspase cleavage sites $\left(\mathrm{DSCD}^{262}, \mathrm{DSFD}^{287} \mathrm{SED}^{290}\right.$ and $\mathrm{DRAD}^{313}$ ) in the exon VII-encoded 794 region of Ets-1 p51. Pointed domain, transactivation domain (TAD), inhibitory domains (I) 795 and DNA binding domain (DBD) are indicated. The caspase cleavage sites are boxed. (A, b) 796 Schematic representation of Cp20, Cp17 and Cp14 fragments generated by cleavage of Ets-1 797 p51 at the putative caspase cleavage sites. (A, c) Sequences of wild-type and mutant (D1N, 798 D3N and D4N) Ets-1 p51, in which Asp (D) residues were mutated to Asn (N). (B) Cleavage 799 of wild-type and mutant Ets-1 p51 by recombinant active caspase-3. pcDNA3 expression 800 vectors encoding wild-type (WT, lanes 1-2) or mutant (D1N, lanes 3-4; D3N, lanes 5-6; D4N, 801 lanes 7-8) Ets-1 p51 were transfected in HEK-293 cells. After $48 \mathrm{~h}$ of transfection, cell lysates 802 (30 $\mu \mathrm{g}$ total proteins) were incubated in the absence (lanes 1, 3, 5 and 7) or in the presence 803 (lanes 2, 4, 6 and 8) of recombinant active caspase-3 $(0.17 \mu \mathrm{M})$ for $4 \mathrm{~h}$ at $37^{\circ} \mathrm{C}$. (C) Cleavage 804 of wild-type and mutant Ets-1 p51 in MDCK cells undergoing apoptosis. pcDNA3 expression 805 vectors encoding wild-type (WT, lanes 1-2) or mutant (D1N, lanes 3-4; D3N, lanes 5-6; D4N, 806 lanes 7-8) Ets-1 p51 were transfected in MDCK cells. After $48 \mathrm{~h}$ of transfection, cells were 807 treated with anisomycin $(10 \mu \mathrm{M})$ (lanes 2, 4, 6 and 8) or left untreated (lanes 1, 3, 5, 7) for 8 808 h. (B and C) Cell lysates (30 $\mu \mathrm{g}$ total proteins) were analysed by Western blot using an anti809 Ets-1 (C-20) antibody. Longer exposure of the same Ets-1 Western blot is shown in the lower 810 panel. 
812 Figure 5 Cp17 binds to the Ets-binding sites (EBS) palindrome of the stromelysin-1 813 promoter and competes with Ets-1 p51 for binding

814 (A) Structure of the Cp17 fragment compared to the full-length Ets-1 p51. Pointed domain, 815 transactivation domain (TAD), inhibitory domains (I) and DNA binding domain (DBD) are 816 indicated. (B) Lysates $(30 \mu \mathrm{g})$ from HEK-293 cells transiently transfected with the empty 817 vector $(1 \mu \mathrm{g}$, lanes $1-4)$, the Cp17 expression vector $(1 \mu \mathrm{g}$; lanes $9-12)$ or the Ets-1 p51 818 recombinant protein $(1 \mu \mathrm{g}$; lanes 5-8) were incubated with wild-type (WT, lanes 1, 3-5, 7-10, 81911 and 12) or EBS mutant (lanes 2, 6 and 10) ${ }^{32}$ P-labelled DNA probes $(0.5 \mathrm{ng})$ in the absence 820 (lanes 1-2, 5-6 and 9-10) or in presence of unlabeled competitors (WT 800X, lanes 3, 7 and 82111 or EBS mutant $800 \mathrm{X}$, lanes 4,8 and 12). DNA/protein complexes were separated by 822 electrophoresis in a 5\% non-denaturing polyacrylamide gel. Arrow 2' indicates potential 823 binary Cp17/DNA complex. Arrows 3 and 3' indicate potential ternary Ets-1 p51/DNA/Ets-1 824 p51 and Cp17/DNA/Cp17 complexes, respectively. (C) Lysates $(30 \mu \mathrm{g})$ from HEK-293 cells

825 transiently transfected with the empty vector $(1 \mu \mathrm{g}$; lanes 1$)$ or increasing concentrations of 826 the Cp17 expression vector (0.45-1 $\mu \mathrm{g}$; lanes 2-5 and 7-10) in the absence (lanes 1-5 and 10) 827 or in the presence of Ets-1 $\mathrm{p} 51$ recombinant protein $(0.5 \mu \mathrm{g}$; lanes 6-10) were incubated with 828 the WT ${ }^{32} \mathrm{P}$-labelled DNA probe $(0.5 \mathrm{ng})$. DNA/protein complexes were separated by 829 electrophoresis in a 5\% non-denaturing polyacrylamide gel. Arrows 3, 3' and 2', as above; 830 arrow $\mathrm{i}$ indicates the putative Ets-1 p51/DNA/Cp17 intermediate ternary complex.

832 Figure 6 Cp17, but not Np36, acts as a dominant negative for transactivation of the 833 stromelysin-1 and collagenase-1 promoters mediated by Ets-1 p51

834 (A) Effect of Cp17 on basal and Ets-1 p51-induced stromelysin-1 promoter activity. pGL3 835 luciferase reporter constructs driven by the stromelysin-1 promoter (200 ng; WT, left panel; 
836 EBS mutant, middle panel) were transfected into HEK-293 cells in the absence (-) or in the 837 presence $(+)$ of Ets-1 p51 expression vector (100 ng; lanes 5-8) and with increasing amounts 838 of the Cp17 expression vector (0-200 ng; lanes 2-4 and 6-8). (B) Effect of Cp17 on Ets-1 p51839 induced collagenase-1 promoter activity. pGL2 luciferase reporter constructs driven by the 840 collagenase- 1 promoter (100 ng; WT, left panel; TORU mutant, middle panel) were 841 transfected into HEK-293 cells in the absence (-) or in the presence $(+)$ of Ets-1 p51 (100 ng; 842 lanes 2 and 4-7), c-Jun (100 ng; lanes 3-7), c-Fos (100 ng; lanes 3-7) and increasing amounts 843 of the Cp17 expression vector (0-100 ng; lanes 5-7). (C) Effect of Np36 on Ets-1 p51-induced 844 stromelysin-1 and collagenase-1 promoter activities. WT stromelysin-1 or collagenase-1 845 promoter reporter vector (stromelysin-1, $200 \mathrm{ng}$, left panel; collagenase-1, $100 \mathrm{ng}$, middle 846 panel) were transfected into HEK-293 cells in the absence (-) or in the presence $(+)$ of the Ets8471 p51 expression vector (100 ng; stromelysin-1, lanes 2-5; collagenase-1, lanes 2 and 4-7), c848 Jun (100 ng; collagenase-1, lanes 3-7), c-Fos (100 ng; collagenase-1, lanes 3-7) and with 849 increasing amounts of the Np36 expression vector (stromelysin-1, 0-200 ng, lanes 3-5; 850 collagenase-1, 0-100 ng, lanes 5-7). (A, B and C) Luciferase activity, measured $48 \mathrm{~h}$ after 851 transfection, was normalised to renilla activity using a pRLnull vector $(1.25 \mathrm{ng})$ and is 852 expressed as the percentage of WT construct activity induced by Ets-1 p51 (stromelysin-1) or 853 by the synergistic effect of Ets-1 p51 and c-Fos/c-Jun (collagenase-1). Cell lysates were 854 analysed by Western blot using indicated antibodies to assess protein expression. Results are 855 the average of two experiments performed in triplicate.

856

857 Figure $7 \quad$ Cp17 decreases the Ets-1 p51 target genes expression

858 Reverse transcription (RT)-PCR analysis of Ets-1 p51 target genes. Empty vector (1 $\mu$ g; lane 859 2), human Ets-1 p51 expression vector (500 ng; lane 3) or human Ets-1 p51 (500 ng) and 860 Cp17 (500 ng) expression vectors (lane 4) were transfected into HIG-82 cells. After 48 h, 
861 RNAs of cells were retrotranscribed and cDNAs were amplified by PCR using $u P A$ and

862 gelatinase $B$ primers (see Experimental). Amplified PCR products were resolved on an

863 agarose gel stained with ethidium bromide. Amplification of human ets- 1 was used to assess

864 expression of the transfected Ets-1 p51 expression vector; amplification of gapdh with

865 specific primers was used as a loading control and amplification without template as a

866 negative control (NC, lane 1). 
A

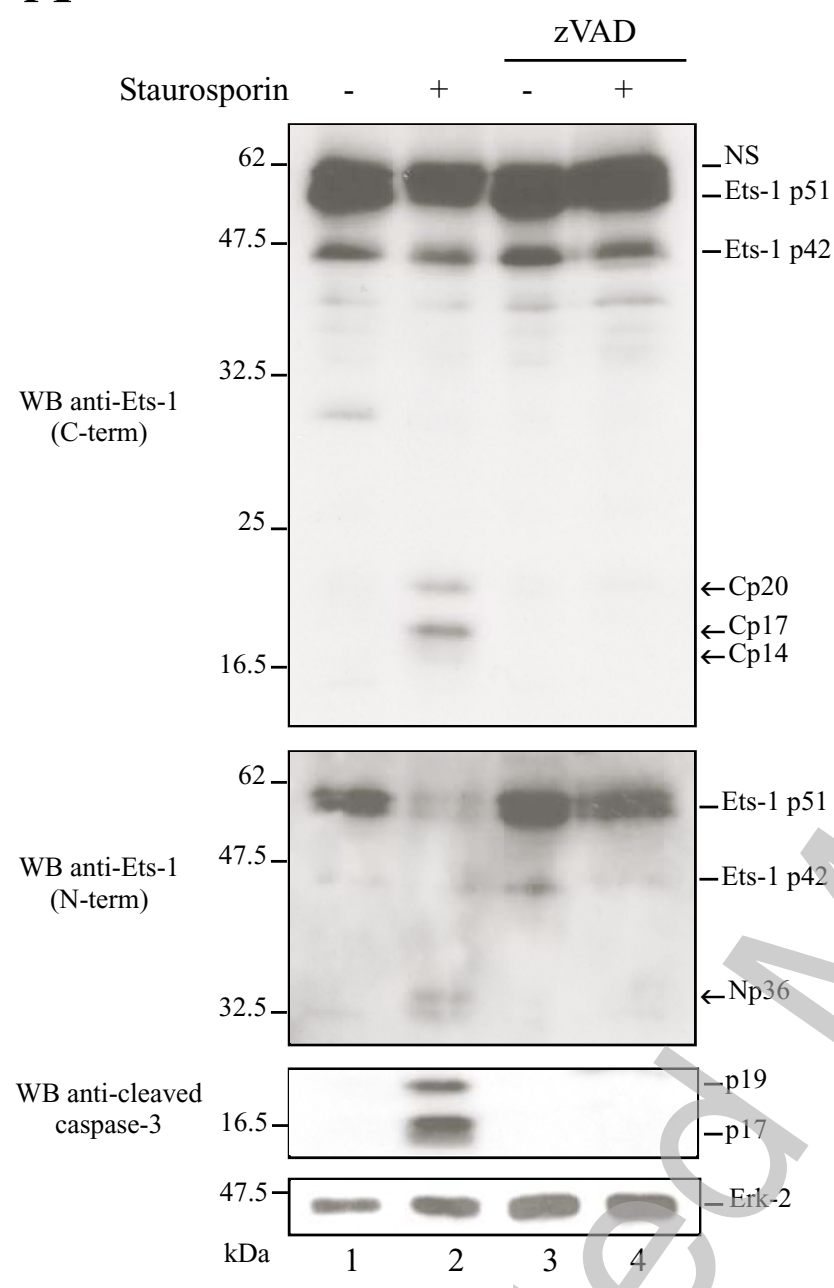

\section{Figure 1}

B

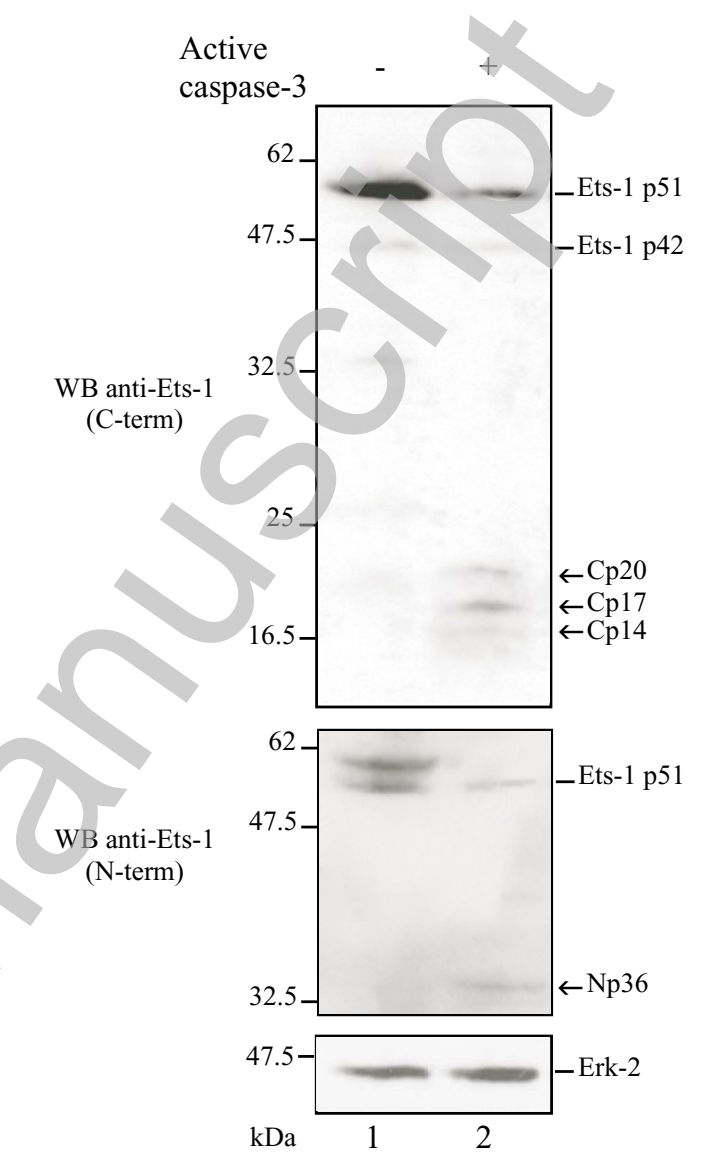




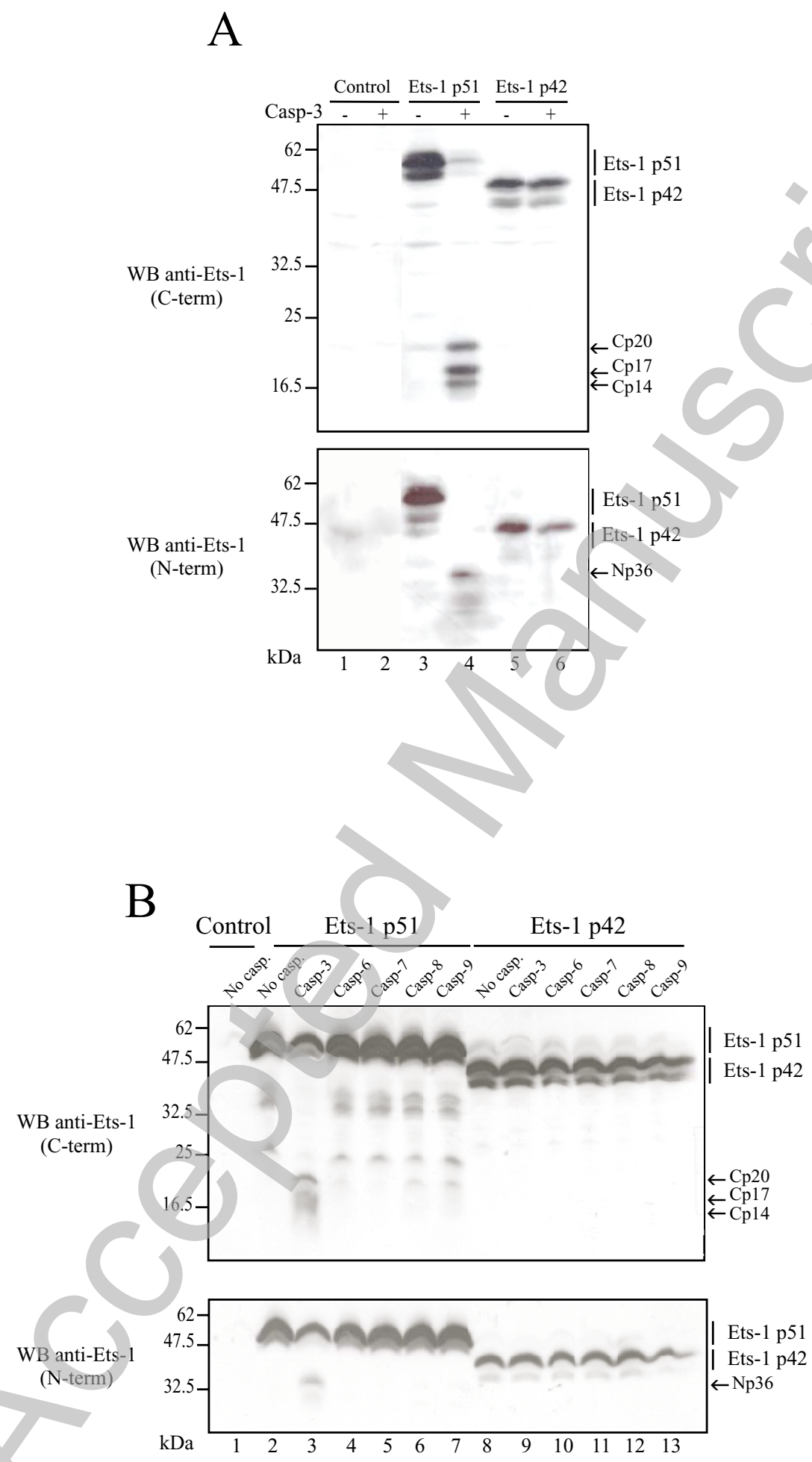


A

$\frac{\text { Control }}{-\quad+\frac{\text { zVAD }}{-+}-+\frac{\text { zVAD }}{-+}-+\frac{\text { zts-1 p51 }}{-++}}$

Figure 3

Staurosporin $-+\frac{\mathrm{zVAD}}{-+}-+\frac{\mathrm{zVAD}}{-+}-+\frac{\mathrm{zVAD}}{-+}$

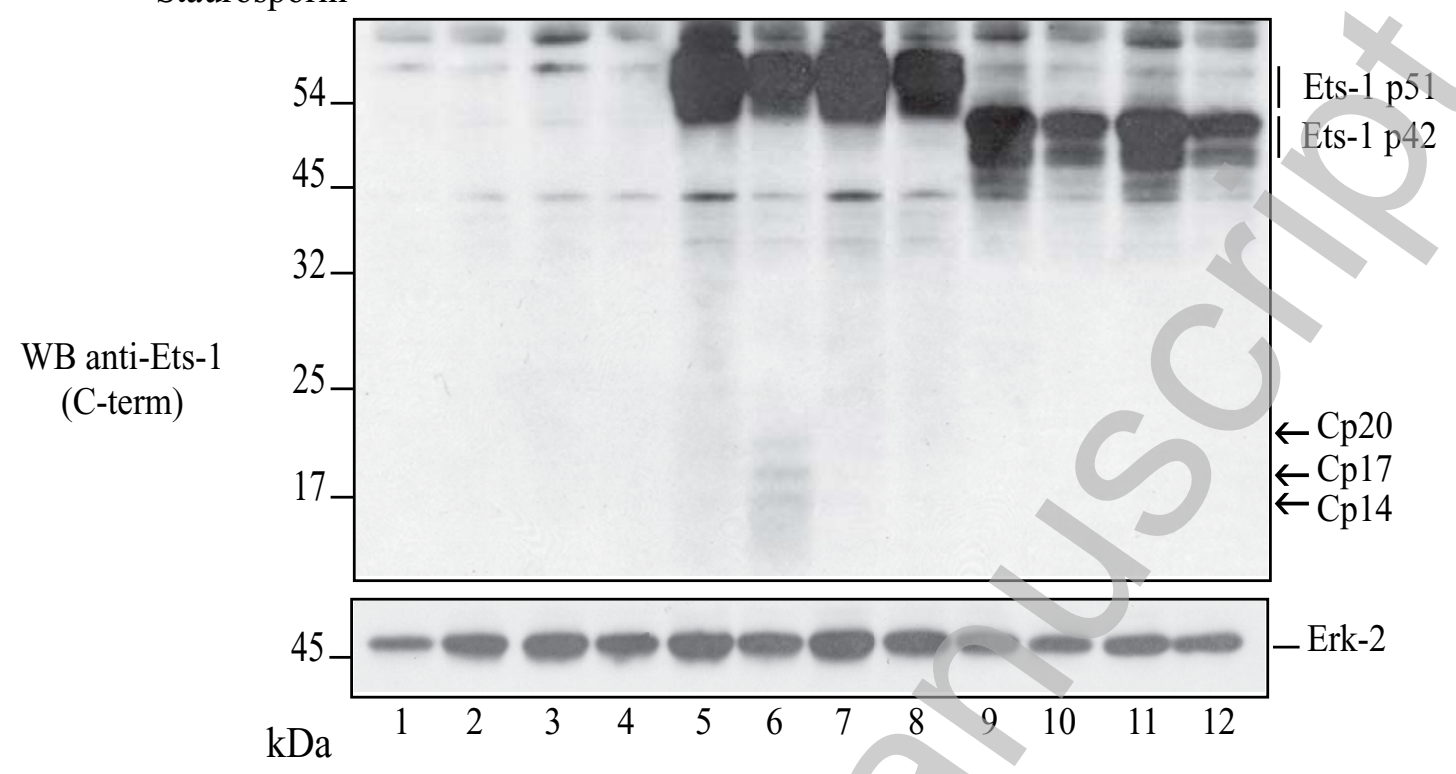

$\mathrm{B}$

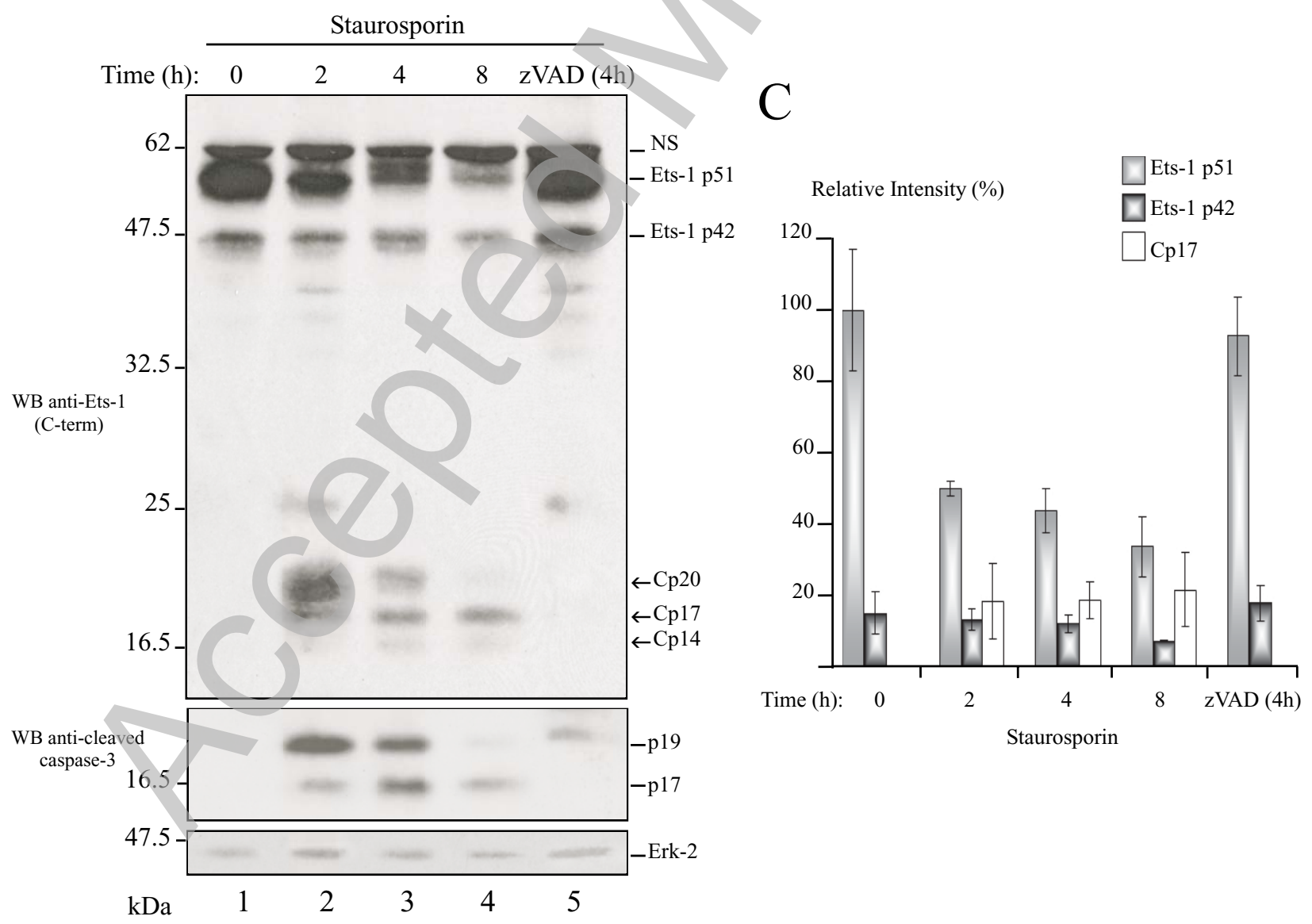


A

(a)

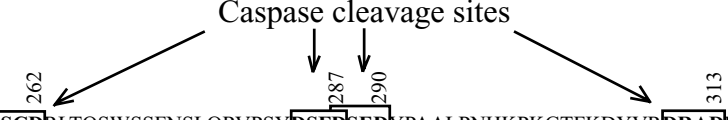

GKLGGQDSFESIESY DSCDRLTQSWSSFNSLQRVPSYDSFDSEDYPAALPNHKPKGTFKDYVR DRADLNKDKPVIPAAALAGYT

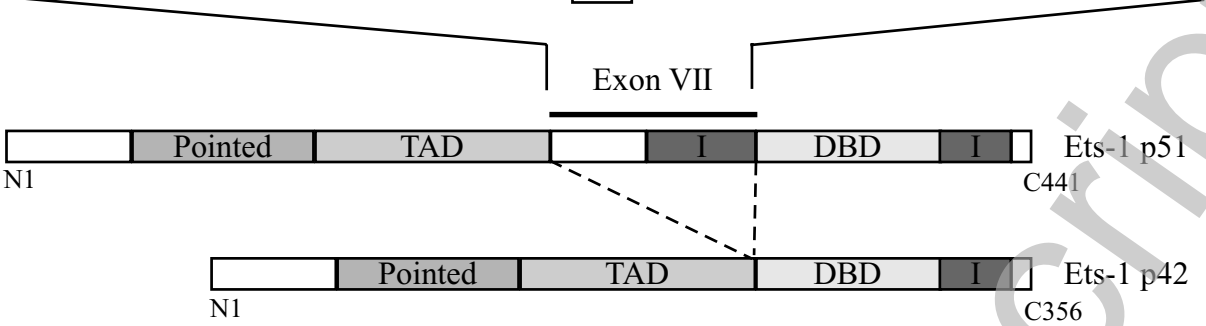

(b)

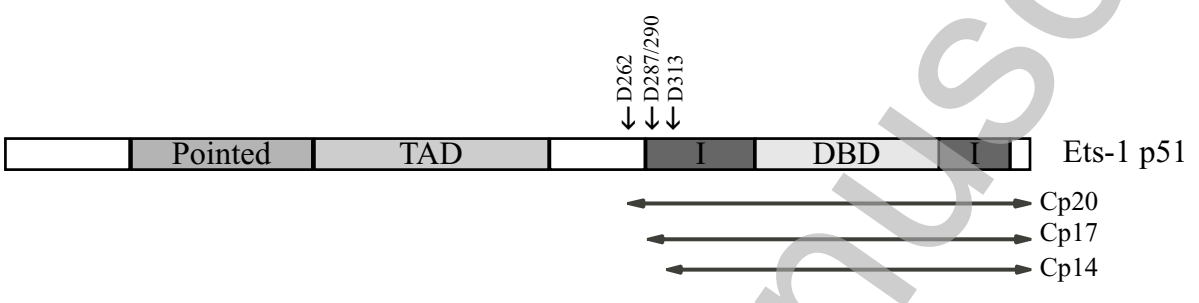

(c)

¿ัن

$\stackrel{\text { के }}{\circ}$

SIESYDSCDRLTQS---//---RVPSYDSFDSEDYPAAL---//--KDYVRDRADLNKDK Wild-type

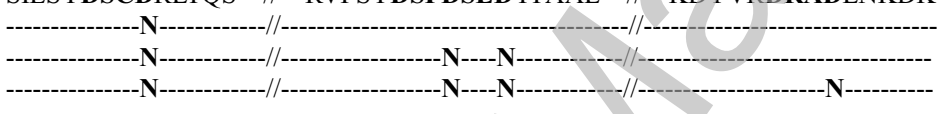

$\mathrm{D} 1 \mathrm{~N}(\mathrm{D} 262 \mathrm{~N})$

D3N (D262/287/290N)

D4N (D262/287/290/313N)

$\mathrm{B}$

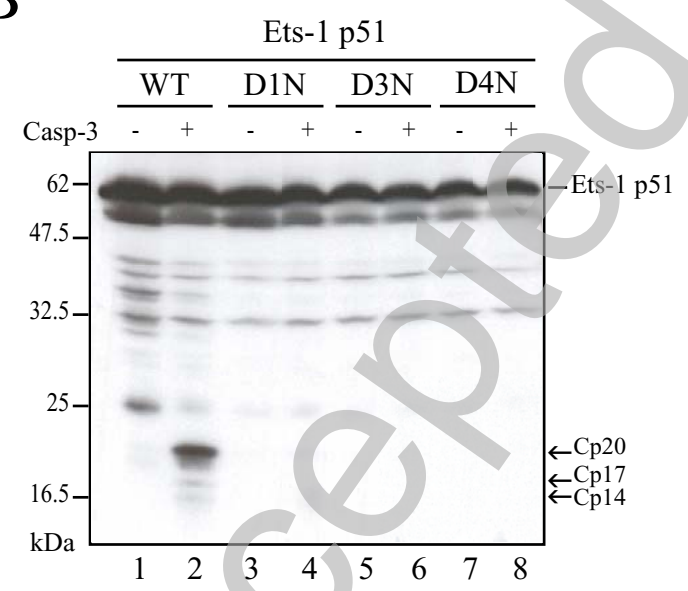

$\mathrm{C}$

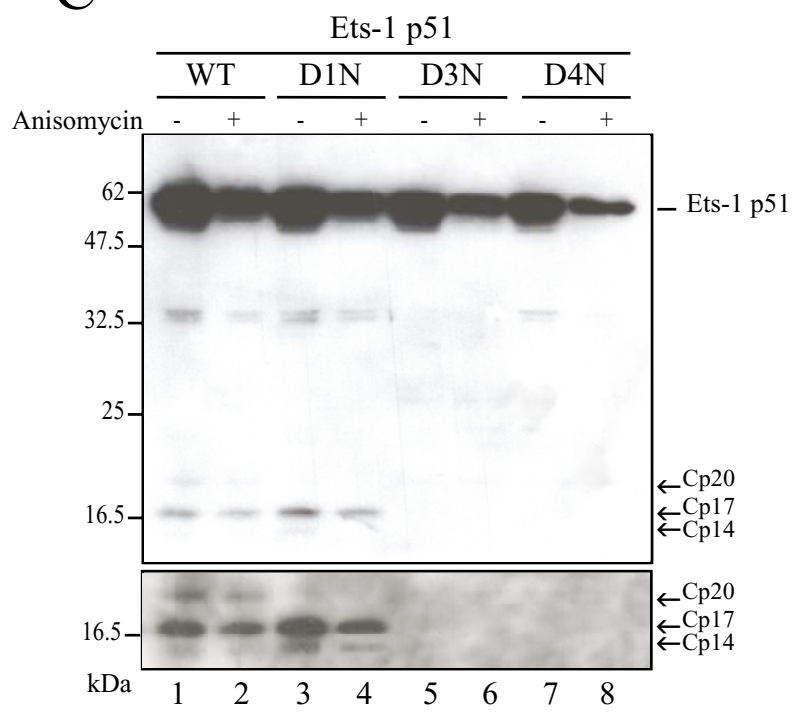

Licenced copy. Copying is not permitted, except with prior permission and as allowed by law. 
A

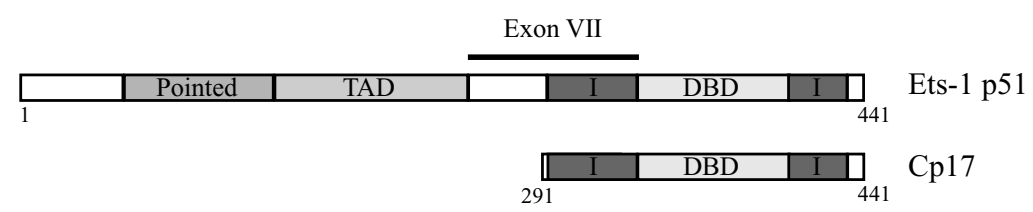

Figure 5

B

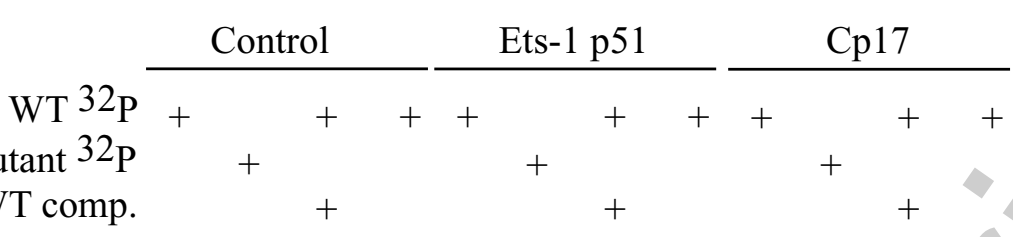

EBS mutant comp.

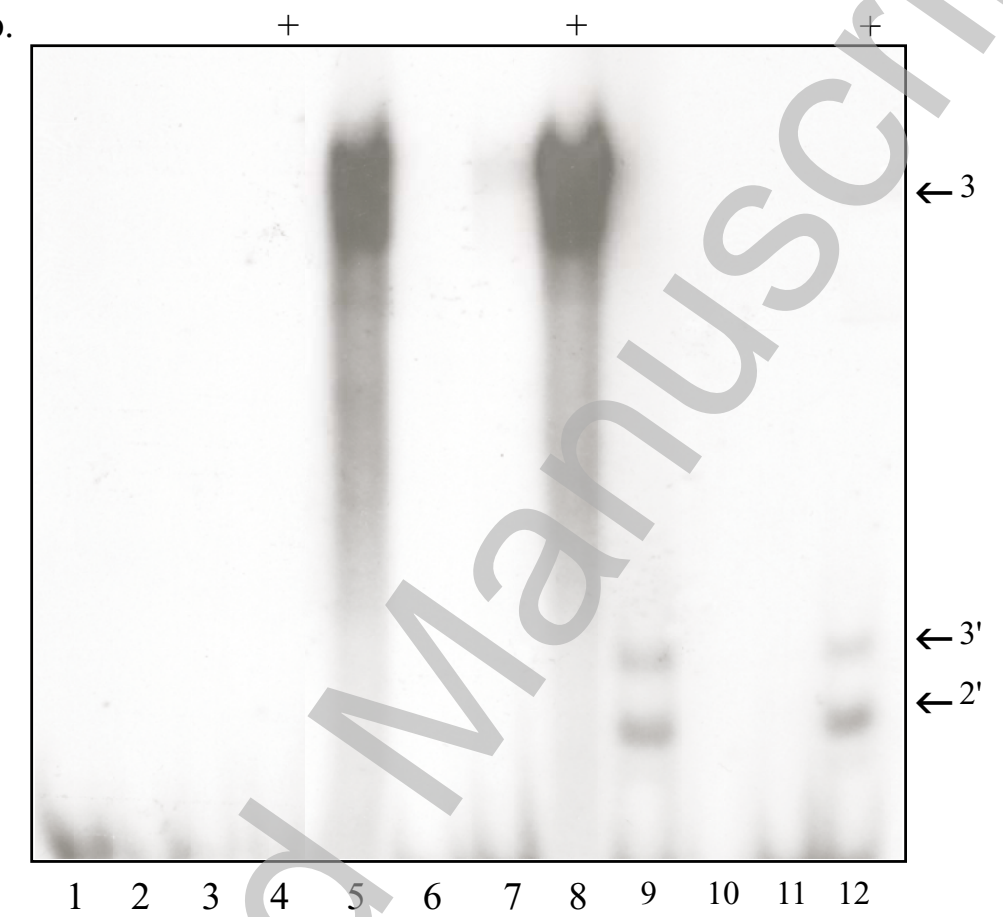

$\mathrm{C}$

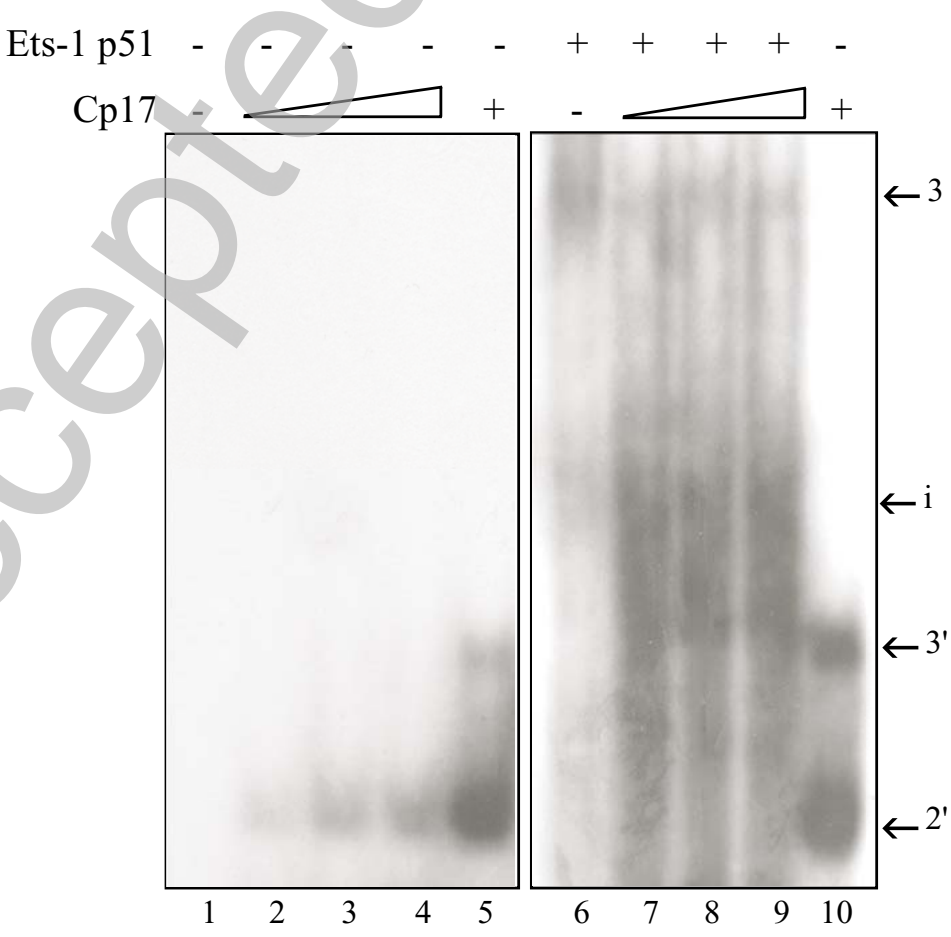


A

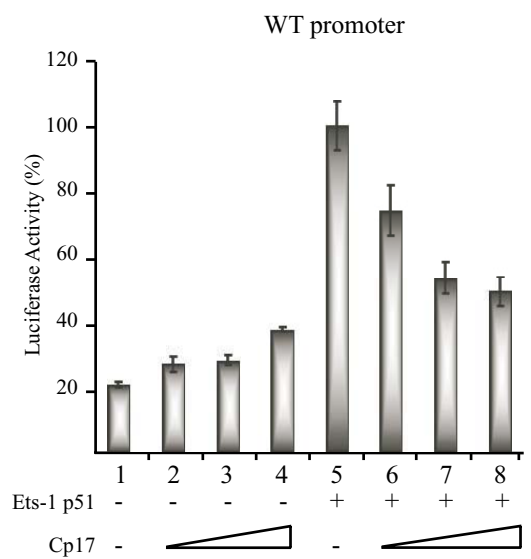

B

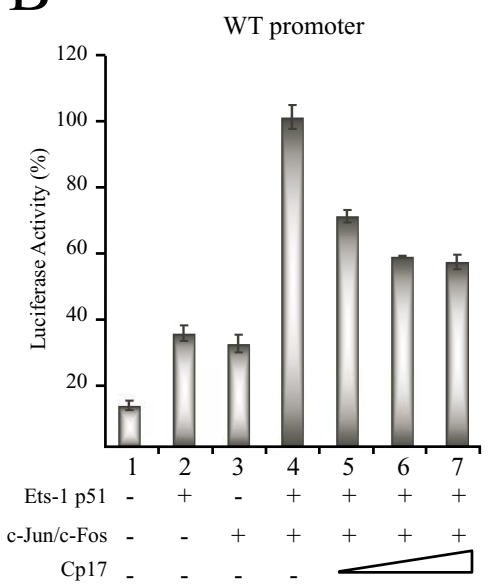

$\mathrm{C}$

WT stromelysin- 1 promoter

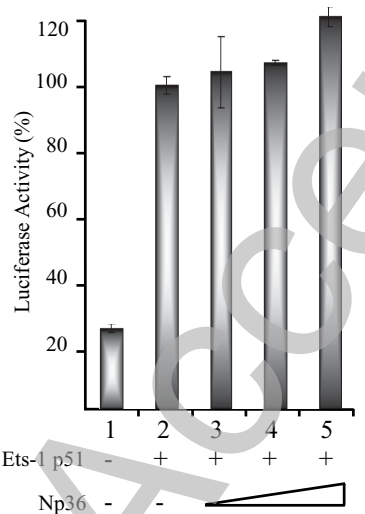

Figure 6
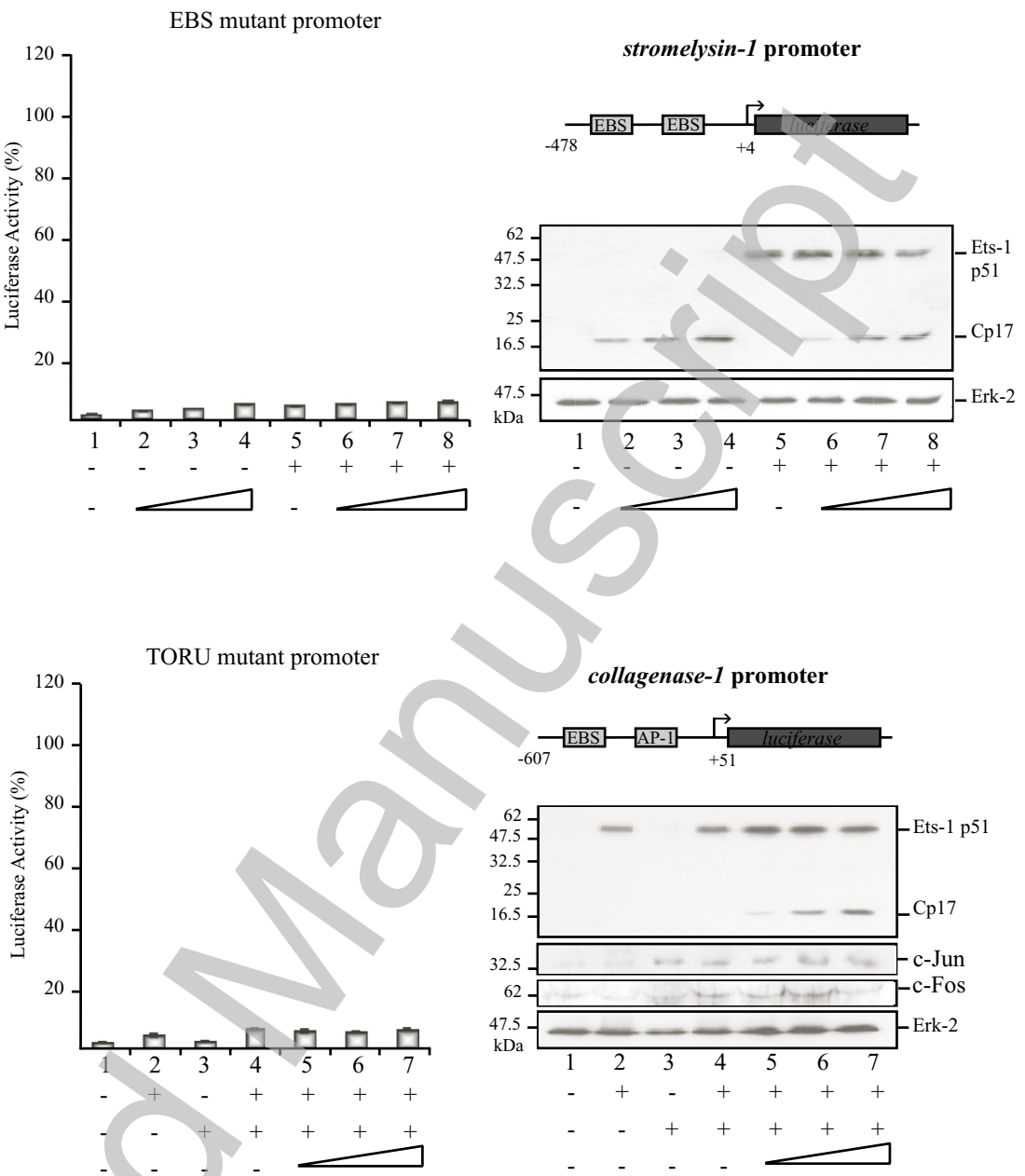

collagenase-1 promoter
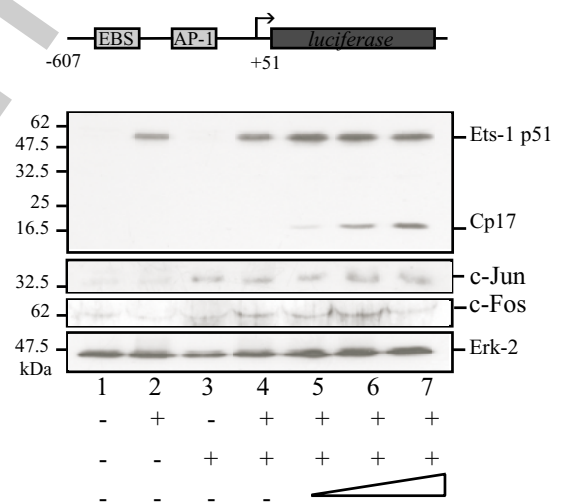

WT collagenase-1 promoter

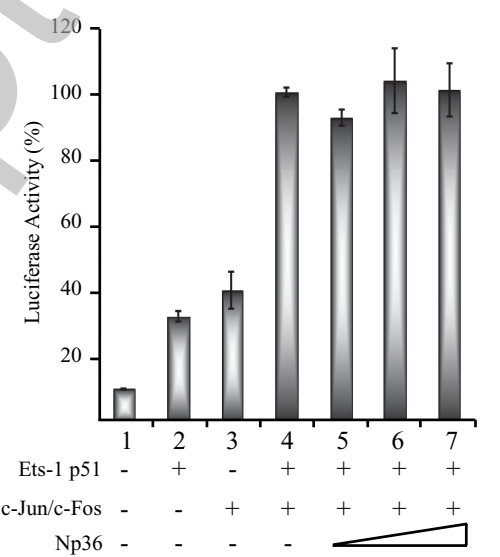

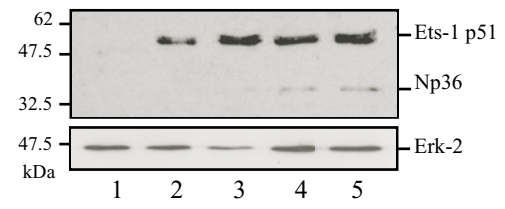

Ets-1 p51 - $+\quad+\quad+\quad+$

Np36 
Figure 7

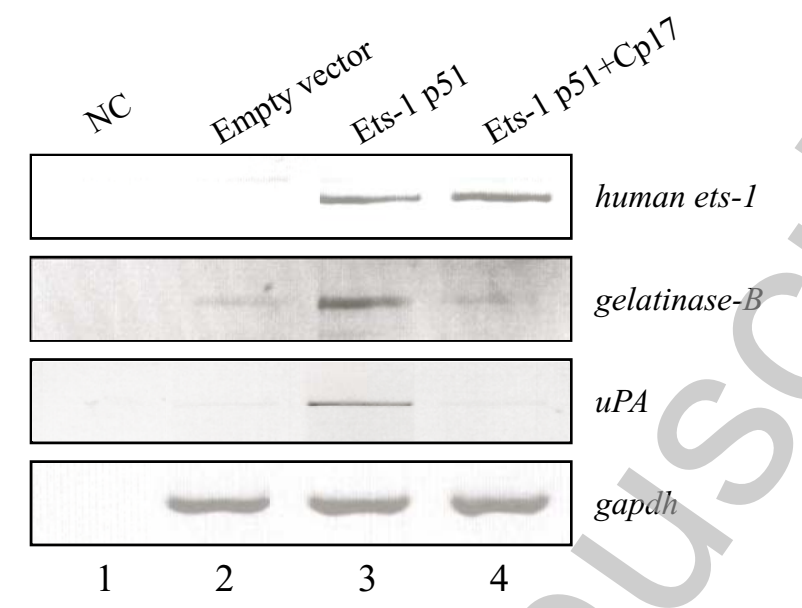

